\title{
Photosynthetic characteristics of cotton are enhanced by altering the timing of mulch film removal
}

\author{
ZHANG Zhanqin ${ }^{1,2}$, ZHANG Li ${ }^{1,2}$, TIAN Haiyan ${ }^{1}$, NIU Yuan ${ }^{3}$ and YANG Xiangkun ${ }^{1,2^{*}}$ (D)
}

\begin{abstract}
Background: The photosynthetic parameters of cotton plants may be modified by the timing of film removal during their growing period. This study was undertaken during 2015-2017 in Xinjiang, China, to determine to what extent the film mulching removal time, 1 and 10 days before the first irrigation and 1 day before the second irrigation after seedling emergence, influenced cotton's photosynthetic characteristics. The control group (CK) was film-mulched throughout the growth stages.

Results: The results suggested the following: (1) Removing mulching-film within 50 days since seedling emergence had adverse effects on soil temperature and moisture. (2) Film-removal before the first or second irrigation after emergence improved the net photosynthetic rate in cotton's later flowering stage and its transpiration rate in mid and later flowering stages while enhancing the actual electron transport rate (ETR) and maximum electron transfer rate (ETRmax) between cotton photosystems I and II. (3) Film-removal treatment also increased cotton plants' tolerance to high irradiation after emergence, the trend was more pronounced in the early flowering stage in wetter years. (4) Leaf area index (LAl) of cotton was reduced in the film-removal treatment for which the least accumulation of dry matter occurred in a drought year (i.e., 2015). (5) Film removal caused a yield decrease in the dry year (2015), and the earlier the film was removed, the more seriously the yield decreased. Removing mulching film before the second irrigation could increase the yield of XLZ42 in the rainy year (2016) and the normal rainfall year (2017). Early film removal can increase the yield of XLZ45 in the rainy year (2016).

Conclusions: Collectively, our study's experimental results indicate that applying mulch film removal at an appropriate, targeted time after seedling emergence had no adverse effects on soil moisture and temperature, and improved the photosynthetic performance of cotton, thus increased cotton yield and fiber quality, but no significant difference was reached.
\end{abstract}

Keywords: Chlorophyll fluorescence, Gas exchange parameters, Lint yield, Removing mulch film, Soil temperature and moisture content

\footnotetext{
* Correspondence: starryyang@sina.com

${ }^{1}$ Xinjiang Academy of Agricultural and Reclamation Science, Shihezi, Xinjiang, China 832000

${ }^{2}$ Key Laboratory of Xinjiang Production and Construction Corps for Cereal Quality Research and Genetic Improvement, Shihezi, Xinjiang, China 832000

Full list of author information is available at the end of the article
}

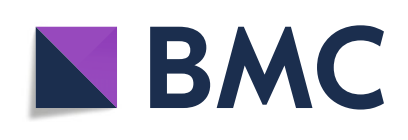

(c) The Author(s). 2021 Open Access This article is licensed under a Creative Commons Attribution 4.0 International License, which permits use, sharing, adaptation, distribution and reproduction in any medium or format, as long as you give appropriate credit to the original author(s) and the source, provide a link to the Creative Commons licence, and indicate if changes were made. The images or other third party material in this article are included in the article's Creative Commons licence, unless indicated otherwise in a credit line to the material. If material is not included in the article's Creative Commons licence and your intended use is not permitted by statutory regulation or exceeds the permitted use, you will need to obtain permission directly from the copyright holder. To view a copy of this licence, visit http://creativecommons.org/licenses/by/4.0/. 


\section{Introduction}

Xinjiang is a domestically and globally important cottongrowing region, where, since the early 1990s, the drip irrigation technique under mulch film ( $\mathrm{Hu}$ and $\mathrm{Li} 2003)$ has been extensively used because it considerably increases cotton production there (Jian et al. 2007; Rao et al. 2016). The cotton-growing industry has expanded greatly: in 2014 the cotton acreage in Xinjiang $\left(2.42 \times 10^{6} \mathrm{hm}^{2}\right)$ was six times its acreage in 1990 (Statistic Bureau of Xinjiang Uygur Autonomous Region, 1990-2014). The cotton yield of Xinjiang now accounts for $>87 \%$ of China's total cotton production and film mulching is now used in $85 \%$ of Xinjiang's cotton fields (Bai et al. 2015).

However, the continuous and widespread application of mulch has led to the problem of plastic film residues, which has reduced cotton production ( $\mathrm{Li} 2016$ ) and damaged farmland ecosystems (Dong et al. 2013; Nkwachukwu et al. 2013; Thompson et al. 2009; Adhikari et al. 2016). The abatement of residual film pollution is now an urgent issue impacting agricultural production in not only Xinjiang but also other arid and semi-arid regions. Yet it is difficult to convince cotton-growers to accept using a degradable mulch film as a substitute for common polyethylene film since it is currently more expensive. Instead, mechanically recycling the plastic film has become a common practice to reduce film residues. More specifically, removing the film only during the key growth stages of cotton lets the film increase soil temperature and conserve soil moisture before its removal time, thus facilitating film recycling while preserving the film's mechanical strength. This is an effective approach to reduce the pollution caused by such film residues.

Previous researches (Li et al. 2010; Su et al. 2011a, b; Xie et al. 2012; Zhang et al. 2016a, b) have mainly focused on how the removal of the cotton field's film layer changed soil temperature and cotton yield. Only a few studies have considered the effects of film-removal on the gas exchange characteristics of crop plants, such as maize (He et al. 1999; Yu et al. 2006; Zhang et al. 2016a) and tobacco (Wang et al. 2010; Yang et al. 2010). Surprisingly, such studies on leaf gas exchange and chlorophyll fluorescence parameters are generally scarce for cotton crops grown.

Photosynthesis is a vital physiological process that is sensitive to water conditions. Besides being affected by stomatal factors, this process is also affected by nonstomatal factors of leaves, such as their chlorophyll content and chloroplast functioning (Zhao et al. 2007). Water availability (Wang et al. 2006) and temperature ( Andersson and Nilsson 2001; Nabi and Mullins 2008; Stone et al. 1999) are the top two crucial factors affecting crop yield in Xinjiang, which is best described as a desert-oasis agriculture region. Therefore, it is curcial to find out what effect the mulch removal has on soil temperature, moisture content, and evaporation in the cotton field, and how cotton photosynthesis changes under this environment, to ensure Xinjiang cotton production.

Studying the photosynthetic characteristics of cotton plant populations at different film removal times can provide valuable knowledge to guide the best practices in cotton production. Here, our study objective was: (1) to investigate the variation in cotton leaf gas exchange and chlorophyll fluorescence parameters of cotton populations across key plant growth stages, and (2) to examine the influence of film removal times on cotton growth, as well as lint cotton yield and its fiber quality; and (3) to provide a scientific basis for reducing residual film pollution in cotton production areas.

\section{Material and methods \\ Study area and design}

The experimental research area was located in Shihezi, Xinjiang, China $\left(44.3108^{\circ} \mathrm{N}, 85.986^{\circ} \mathrm{E}\right.$; elevation: $460 \mathrm{~m})$. We established and replicated the field experiment yearly over 3 years (2015-2017) by using a split-plot experimental design with three replicates per treatment. The main plot level was two varieties of Gossypium hirsutum L. with different water sensitivity (XLZ 42 and XLZ 45), and the subplot level was treated with different film removal times. Three treatments of mulch film-removal time were applied: 10 days (T10) and 1 day (T1) before the first irrigation and 1 day (E1) before the second irrigation after seedling emergence, with one control group of film mulching present across growth stages (CK). Four subplots were randomly arranged in every main plot and replicated three times, amounting to 24 subplots in this experiment. Each subplot is $20 \mathrm{~m}$ long, $4.2 \mathrm{~m}$ wide and covers an area of $84 \mathrm{~m}^{2}$. There were two plastic films, and 12 rows of cotton were planted in each subplot. The plant spacing of cotton was $10 \mathrm{~cm}$ and there were 2400 cotton plants in each plot. The two varieties were arranged interspecifically in the field, such that, XLZ42 was on one film, but XLZ45 on the next one, with this alternation continued. No buffer space was used between adjacent subplots.

Cotton seeds were purchased at the local market. In 2015, these seeds were sown by cotton planters on 24 April; they germinated on 6 May and plants were harvested on 10 September. In 2016, both cotton varieties were likewise sown on 5 May, germinated on 16 May, and harvested on 26 September. In 2017, they were sown on 21 April, germinated on 28 April, and harvested on 6 September. The length of the seasonal cotton-growing period in 2015, 2016, and 2017 was 127, 134, and 131 days, respectively. Mulch film was removed manually at 19 (T10, May 25), 29 (T1, June 4), and 39 (E1, June 14) days after emergence in 2015; at 24 (T10, June 9), 34 
(T1 June 19), 44 (E1, June 29) days after emergence in 2016; at 33 (T10, May 31), 43 (T1, June 10), 53 (E1, June 20) days after emergence in 2017.

The average air temperature, $\geq 10^{\circ} \mathrm{C}$ active accumulated temperature, and precipitation from May to September, was $22.86^{\circ} \mathrm{C}, 3014{ }^{\circ} \mathrm{C}$, and $94 \mathrm{~mm}$ in 2015; $22.58^{\circ} \mathrm{C}, 3165^{\circ} \mathrm{C}, 120.2 \mathrm{~mm}$ in 2016 ; and $22.45^{\circ} \mathrm{C}$, $3413^{\circ} \mathrm{C}$, and $96.5 \mathrm{~mm}$ in 2017 (the meteorological data were obtained from the Shihezi Weather Bureau). The basic physical and chemical properties of soil in the experimental area, and the latter's cropping pattern and field management practices could refer to Yang et al. (2017).

\section{Sample collection and determination}

\section{Soil temperature measurement and calculation}

After the cotton sowing, MicroLite USB Loggers (Fourier Technologies Ltd. Rosh, Haayin, Israel) were buried in the middle of each wide and narrow row of XLZ42 in the four treatments at depths of $10 \mathrm{~cm}, 20$ $\mathrm{cm}$, and $30 \mathrm{~cm}$ (Fig. 1). So, in all, 24 data loggers were thus buried. Data was collected hourly; the daily average temperature was the mean value of 24 recorded values per day.

Accumulated soil temperature of different periods, similar to the accumulated air temperature, is the sum of daily average soil temperatures of different soil layers during different periods. Average soil temperature is the mean value of accumulated soil temperature during a given period. The daily soil temperature difference is the difference between the maximum and minimum daily temperatures. The accumulated soil temperature difference is the summed daily soil temperature difference during a given period. The average soil temperature difference is the mean value of accumulated soil temperature difference for a given period. For calculation methods refer to Chen (2005).

\section{Measurement and calculation of soil moisture content}

One week before the removal of film in 2017, a PR2 Profile Probe (Delta-T Devices Ltd., Burwell, Cambridge, UK) was buried in the middle of each of the wide and narrow rows of XLZ42 in the four treatments (Fig. 1); hence a total of eight probes were buried. During the 33-55 days since seedling emergence, the volumetric moisture contents of the $0-10$, $10-20, \quad 20-30,30-40,40-60$, and $60-100 \mathrm{~cm}$ soil layers were monitored daily. After 55 days postemergence these measurements were taken once every 4 days, plus an extra additional measurement made before and after each irrigation event.

\section{Gas-exchange parameters of cotton}

The Li-6 400 XT portable photosynthesis system (LiCor Inc., Lincoln, USA) was used to monitor the gas exchange parameters of cotton (XLZ42 and XLZ45) leaves at $5,15,25,35$, and 45 days after flowering. The standard leaf chamber $(2 \mathrm{~cm} \times 3 \mathrm{~cm})$ was used, and three plants were measured in this way per treatment combination (variety $\times$ removal time; the same for below). Each treatment combination thus had replicated three times. In each case, the sampling time of measurement was between 12:00 and 14:00, when the it was clear and cloudless. The second leaf from top to bottom on the main stem was measured per plant. To reduce the error and ensure the consistency of these in situ measurements, we applied the method of Zhan (2014); briefly, approximately 100 leaves from 100 plants with uniform growth were first marked, with the same leaves measured each time.

The measured leaf parameters were as follows: Pn (photosynthetic rate, $\mu \mathrm{mol} \mathrm{CO} \cdot \mathrm{m}^{-2} \cdot \mathrm{s}^{-1}$ ), Trmmol (transpiration rate, $\mathrm{mmol} \mathrm{H}_{2} \mathrm{O} \cdot \mathrm{m}^{-2} \cdot \mathrm{s}^{-1}$ ), Cond (conductance to $\mathrm{H}_{2} \mathrm{O}, \mathrm{mmol} \mathrm{H}_{2} \mathrm{O} \cdot \mathrm{m}^{-2} \cdot \mathrm{s}^{-1}$ ), $\mathrm{Ci}$ (intercellular $\mathrm{CO}_{2}$ concentration, $\mu \mathrm{mol} \cdot \mathrm{mol}^{-1}$ ), PAR (photosynthetic active

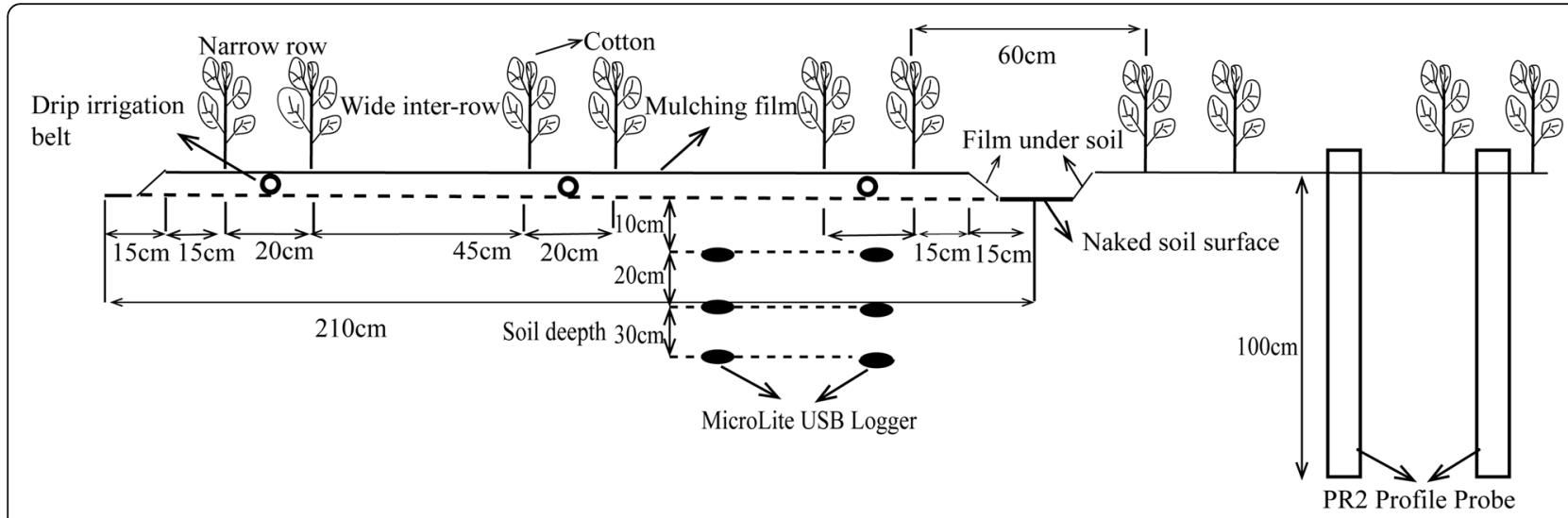

Fig. 1 Cropping pattern and burial depth of MicroLite USB Loggers and PR2 Profile Probe in the mulching film-removal field experiment 
radiation, $\mu \mathrm{mol}$ photons $\cdot \mathrm{m}^{-2} \cdot \mathrm{s}^{-1}$ ) and $\mathrm{Ca}$ (atmospheric $\mathrm{CO}_{2}$ concentration, $\mu \mathrm{mol} \cdot \mathrm{mol}^{-1}$ ).

The stoma limit value (Ls) was calculated as $\mathrm{Ls}=1$ - (Ci/Ca) (Berry and Downton 1982). Water use efficiency (WUE) and intrinsic WUE (WUEi) were calculated according to the equations of WUE $=\mathrm{Pn} /$ Trmmol and WUEi $=\mathrm{Pn} /$ Cond (Peñuelas et al. 1998). Light use efficiency (LUE) was calculated as LUE $=($ Pn / PAR $) \times 100 \%$ (Li et al. 2014a, b).

\section{Chlorophyll fluorescence parameters of cotton leaf}

A PAM-2500 portable modulated chlorophyll fluorometer (Heinz Walz GmbH, Eichenring, Effeltrich, Germany) was used to quantify the chlorophyll fluorescence parameters of the leaf in same position of the sampled cotton plants. For each treatment combination three replicate plants were used. Each treatment combination thus had three replicates. Their measuring time was between 8:00 and 12:00 on the same day the gas exchange parameters were measured, with a 2030-B leaf clip used. Before their determination, the leaf was fully dark-adapted for about $30 \mathrm{~min}$. We then set the measuring light intensity to $102 \mu \mathrm{mol} \cdot \mathrm{m}^{-2}$. $\mathrm{s}^{-1}$ and the actinic light intensity to $713 \mu \mathrm{mol} \cdot \mathrm{m}^{-2}$. $\mathrm{s}^{-1}$. The time interval between the first saturating pulse and open actinic light was $40 \mathrm{~s}$, with a 20 -s time interval between each saturating pulse after turning on the actinic light (width of $310 \mathrm{~S}$ ). The saturating pulse intensity in the quenching analysis was $17250 \mu \mathrm{mol} \cdot \mathrm{m}^{-2} \cdot \mathrm{s}^{-1}$. Then, we transferred to the "Slow Kinetics Window" and started its automatic program to determine the slow-induction parameters. The following parameters were considered: F0 (original fluorescence), Fm (maximal fluorescence), $\mathrm{F}^{\prime}$ (fluorescence at any time), Fm' (maximal Fluorescence at light adaptation), and Fo' (minimal fluorescence at light adaptation). The remaining fluorescence parameters were calculated according to established methods: $\mathrm{Fv} / \mathrm{Fm}$ was used to express the maximum photochemical quantum yield of photoreaction system II (PS-II) (Kitajima and Butler 1975), Y (II) is the actual photochemical quantum yield of PS-II (Genty et al. 1989), qL is the coefficient of photochemical fluorescence quenching, assuming interconnected PS II antennae and lake model (Kramer et al. 2004), NPQ is the SternVolmer type non-photochemical fluorescence quenching (Bilger and Björkman 1990), Y (NO) is the quantum yield of non-light-induced nonphotochemical fluorescence quenching (Kramer et al. 2004), and Y (NPQ) expressed the quantum yield of light-induced (i.e., $\Delta \mathrm{pH}$ and zeaxanthindependent) non-photochemical fluorescence quenching (Kramer et al. 2004).

\section{Fitting the light curve}

To do this, we determined the relative electron transfer rate $\left(\mathrm{rETR}, \mu \mathrm{mol} \cdot \mathrm{m}^{-2} \cdot \mathrm{s}^{-1}\right)$ under different intensities of PAR (9, 65, 111, 205, 352, 570, 722, 921, 1 298, 1 796, and $\left.2139 \mu \mathrm{mol} \cdot \mathrm{m}^{-2} \cdot \mathrm{s}^{-1}\right)$. Each level of PAR lasted $20 \mathrm{~s}$, with three replicates used per treatment combination. We used Pamwin-3 (the operating software of the PAM2500 device) to fit curves to this collected data. The fitting formula used was ETR $=\mathrm{PAR} /\left(\mathrm{a} \cdot \mathrm{PAR}^{2}+\mathrm{b} \cdot \mathrm{PAR}+\mathrm{c}\right)$ (Eilers and Peeters 1988).

Fitting parameters consisted of an initial slope of the fast light curve ( $\alpha$, electrons photons ${ }^{-1}$, conveying the efficiency of light energy utilization), the minimum saturating irradiance $\left(\mathrm{Ik}\right.$, in $\mu \mathrm{mol} \cdot \mathrm{m}^{-2} \cdot \mathrm{s}^{-1}$, corresponding to plant tolerance of intense light), and the maximum electron transfer rate (ETRmax, in $\left.\mu \mathrm{mol} \cdot \mathrm{m}^{-2} \cdot \mathrm{s}^{-1}\right)$. The calculation formulas for each parameter were $\alpha=1 / \mathrm{c}$; $\operatorname{ETRmax}=1 /(\mathrm{b}+2 \cdot \sqrt{a \cdot \mathrm{c}}) ; \mathrm{I}_{\mathrm{k}}=\mathrm{c} /(\mathrm{b}+2 \cdot \sqrt{a \cdot \mathrm{c}})$.

\section{Dry matter accumulation, canopy structure, lint yield and fiber quality characters of cotton}

Cotton plants - their shoots and roots in the $0-30 \mathrm{~cm}$ soil layer-were sampled in each subplot every 14 days from day 33 (2017), day 21 (2016) and day 35 (2015) since seedling emergence. The details of this sample collection and determination could refer to Yang et al. (2017). Further, an LAI-2200C plant canopy analyzer (Li-Cor Inc., Lincoln, USA) was used to measure and determine the leaf area index (LAI) of cotton, following Malone et al. (2002). LAI values were measured once between two wide rows and three narrow rows in each treatment, and the average value of these five values was used as the LAI values in this treatment. Yield and fiber quality characters of harvested cotton were measured according to Yang et al. (2017).

\section{Data analysis}

Data processing and figure drawing were performed with Microsoft Excel 2010 (Microsoft Corporation, Redmond, USA) and SigmaPlot 12.5 (Systat Software Inc., San Jose, USA), respectively.

The MANOVA (multi-factor analysis of variance) was carried out with univariate GLM (general linear model). The number of days after flowering $(\mathrm{df}=4)$, filmremoval time $(\mathrm{df}=3)$, and cotton variety $(\mathrm{df}=1)$ were used as fixed factors, and the different photosynthetic characteristics were used as the dependent variables, respectively, in each GLM. The fixed factors had significant effects on cotton's photosynthetic characteristics was examined by conducting multiple comparisons using LSD (least significant difference) tests at an alpha level $=0.05$. Associations between net photosynthetic rate $(\mathrm{Pn})$ and other gas exchange parameters in various treatment groups were investigated with Pearson 
correlations $(n=30)$ in a two-tailed test (*, $P<0.05$, **, $P<0.01)$. These analyses were carried out in SPSS 23.0 statistical software (International Business Machines Corp, Armonk, USA).

Dry matter accumulation of cotton was modeled using a logistic equation: $\mathrm{Y}=\mathrm{K} /(1+\mathrm{EXP}[\mathrm{a}+\mathrm{bt}])$. The method developed by Ming (2006) was used to calculate the following parameters: Rmax represents the largest dry matter accumulation rate at Tmax, which is the time at which cotton dry matter accumulation rate has reached its maximum; the weight of dry matter at Tmax is given by Wm. The time point when rectilinear accumulation starts is recorded as $\mathrm{t} 1$ and when it ends accumulation ends as $\mathrm{t} 2$; hence $\Delta \mathrm{W}_{\mathrm{t} 2^{-} \mathrm{t} 1}$ represents dry matter accumulated from $\mathrm{t} 1$ to t2. This analysis was performed in DPS 16.05 (Tang and Zhang 2012) using the Marquardt method.

\section{Results}

\section{Soil temperature and moisture among film-removal} treatments

Within 1 to 50 days after seedling emergence, the soil temperatures of all soil layers in the film-removal treatments were lower than those of CK. After the 50-day mark, however, the gap gradually narrowed until it reversed, becoming higher than under CK (Fig. 2). Soil average temperature, accumulated temperature, and mean temperature difference (Table 1 ) in the $0-30 \mathrm{~cm}$ soil layer during the entire growth period were highest in $\mathrm{CK}$ in $2015\left(23.19^{\circ} \mathrm{C}, 2533^{\circ} \mathrm{C}\right.$, and $5.94{ }^{\circ} \mathrm{C}$, respectively) and T10 treatment in $2016\left(22.93{ }^{\circ} \mathrm{C}, 2583^{\circ} \mathrm{C}\right.$, and $2.98^{\circ} \mathrm{C}$, respectively). In each experimental year, the accumulated temperature difference (Table 1 ) was the highest in $\mathrm{CK}$, at $648^{\circ} \mathrm{C}(2015)$ and $145^{\circ} \mathrm{C}(2016)$.

From 37 days post-emergence to the first irrigation (i.e., 42 days since emergence), soil moisture content (V/ $\mathrm{V}$; the same blow) in the $0-10 \mathrm{~cm}$ soil layer was highest in CK, while for the $10-20 \mathrm{~cm}$ soil layer it was the highest in the T10 treatment. In deeper soil $(40-100 \mathrm{~cm}$ soil layer), the soil moisture content of $\mathrm{CK}$ was the highest among treatments. From the first to second irrigation (43-52 days after emergence), soil moisture content under CK in soil $0-30 \mathrm{~cm}$ deep increased slightly, but differences between treatments were not obvious. The rank order of moisture content in the $30-100 \mathrm{~cm}$ soil layer was thus $\mathrm{T} 1>\mathrm{CK}>\mathrm{T} 10$, and the deeper the soil layer, the greater the gap in moisture content found between treatments (Fig. 3).

After the second irrigation (53 days after emergence), the soil moisture content of $\mathrm{CK}$ was the greatest in the $0-60 \mathrm{~cm}$ soil layer, while that under the T1 treatment was the highest for the 60 $100 \mathrm{~cm}$ layer. From the $20-\mathrm{cm}$ depth mark and downward, T10 consistently had the lowest moisture content (Fig. 3).
Gas exchange parameters of film-removal treatments at different days since flowering

The net photosynthetic rate (Pn, Fig. 4a) of film-removal treatments exceeded that of $\mathrm{CK}$ at 45 days after flowering, while at the early flowering stage there were no significant differences among the treatments. Nonetheless, the film-removal treatment early in the flowering of XLZ45 in 2017 had a slightly lower Pn than that under CK, whereas other film-removal treatments had Pn values slightly greater than CK's.

At 5 days after flowering in 2017, relative to CK, the Pn (Fig. 4a), Cond (Fig. 4b) and Ci (Fig. 4c) values of XLZ45 under all film-removal treatments were lower but their Ls value was much higher (Fig. 4d). This indicated that the decreased photosynthetic rates of cotton plants in those film-removal treatments were driven by reductions in stomatal conductance.

However, at 45 days after flowering, the Pn (Fig. 4a), Cond (Fig. 4b) in 2016/2017 and Ci (Fig. 4c) in 2016 of CK were lower than those recorded in the T1 and T10 treatments, while the Ls value (Fig. 4d) of CK in 2016 was higher than those of T1 and T10 treatments; hence, this indicated that in the years with more rainfall (i.e., 2016), the net photosynthetic rate declined at later growth stages because of lower stomatal conductance. But in 2017, when rainfall was normal, the decreased net photosynthetic rate of CK was mainly caused by nonstomatal factors.

The MANOVA (Table S1) showed that different flowering days had a significant impact on $\mathrm{Pn}$, Cond, $\mathrm{Ci}$, and Ls, while treatments differed in their significant impacts on Pn (2016/2017), Cond (2016/2017), and Ci (2016), whereas the cotton variety growth had a significant impact only on Pn (2016/2017) and Cond (2016).

According to the correlation coefficients of Pn with other gas exchange parameters of different treatments in 2016 and 2017 (Table 2), the association between Pn and Cond or LUE of each treatment in 2016 was stronger than that in 2017, whereas Pn and WUE were more strongly associated in 2017 than those in 2016. This indicated that cotton's photosynthetic rate was mainly affected by light energy utilization rate and stomatal factors in the year (2016) with heavy rainfall, yet in a normal rainfall year (2017) soil water status has a greater influence on photosynthesis.

\section{Chlorophyll fluorescence parameters of cotton leaves among film-removal treatments at different days since flowering \\ Influence of mulch film removal on the maximum photochemical quantum yield of PS-II (Fv/Fm) and actual photochemical quantum yield of PS-II (Y (II))}

In the early stage of flowering (i.e., 5 days postflowering), $\mathrm{Fv} / \mathrm{Fm}$ of $\mathrm{CK}$ was the highest. As the cotton 


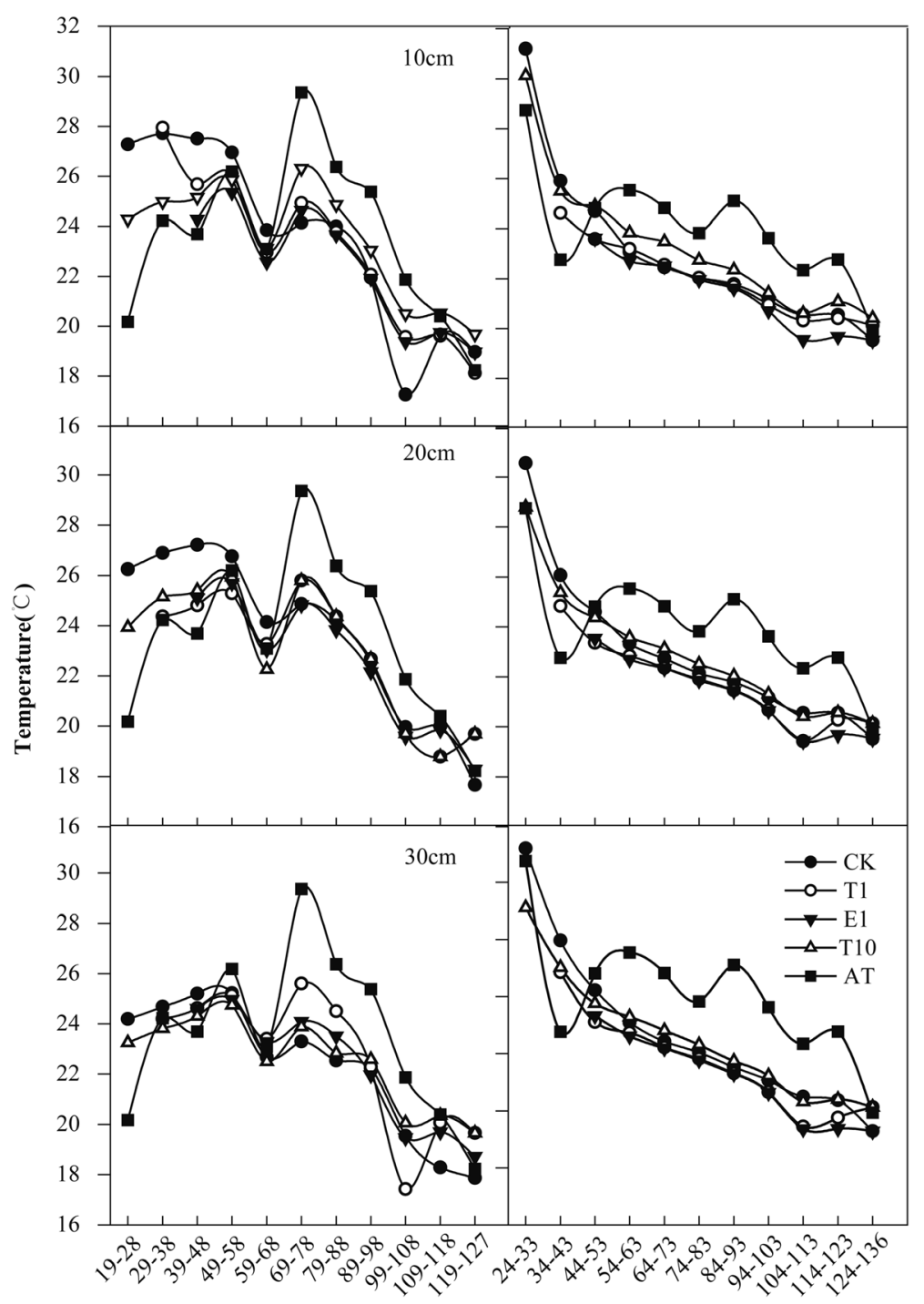

Days after emergence(d)

Fig. 2 Daily average soil temperature $\left({ }^{\circ} \mathrm{C}\right)$ variation in various treatment groups: 1 and 10 days before the first irrigation $(\mathrm{T} 1, \mathrm{~T} 10$, respectively) and 1 day before the second irrigation (E1) after seedling emergence, with one control group of film mulching present across cotton plant growth stages (CK) and soil depth layers (10, 20, and $30 \mathrm{~cm}$ ) across growth stages during 2015-2016. AT is air temperature. A and D represent the removal of mulch 10 days before the first irrigation on May 25, 2015 and June 9, 2016, respectively. B and E represent the removal of mulching film on June 4, 2015 and June 19, 2016, respectively, one day before the first irrigation. C and F represent the removal of mulching film on June 14, 2015 and June 29, 2016, respectively, one day before the second irrigation

grew, the gap in Fv/Fm values between the CK and filmremoval treatments gradually narrowed, with $\mathrm{Fv} / \mathrm{Fm}$ under the film-removal treatments eventually surpassing that of CK. However, at 45 days post-flowering, except for $\mathrm{Fv} / \mathrm{Fm}$ of XLZ42 plants in 2017 being significantly higher than CK, the Fv/Fm values for the film-removal treatment of different cotton varieties were all lower than CK's (Fig. 5). The MANOVA showed that only the number of days since flowering in either year had a significant impact on $\mathrm{Fv} / \mathrm{Fm}$, whereas it was similar among film-removal treatments (Table S1).

In 2017, removing the film mulching reduced the $\mathrm{Y}$ (II) value at the early flowering stage, then increased significantly, especially in the late growth stages; the Y (II) value increased obviously when film was removed earliest (T10). However, in the heavy rainfall year (2016), removing the film significantly increase Y (II) at the early 


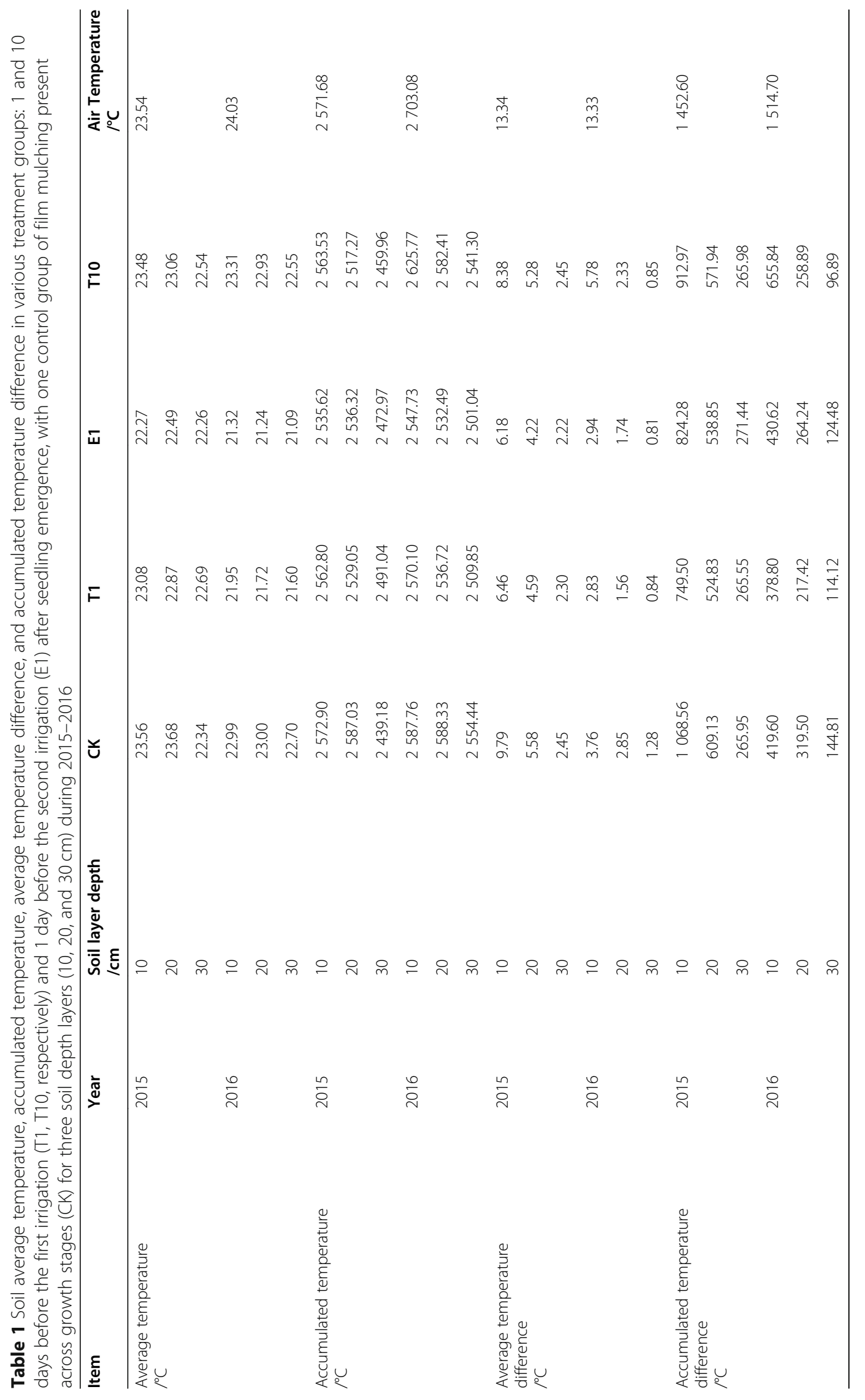




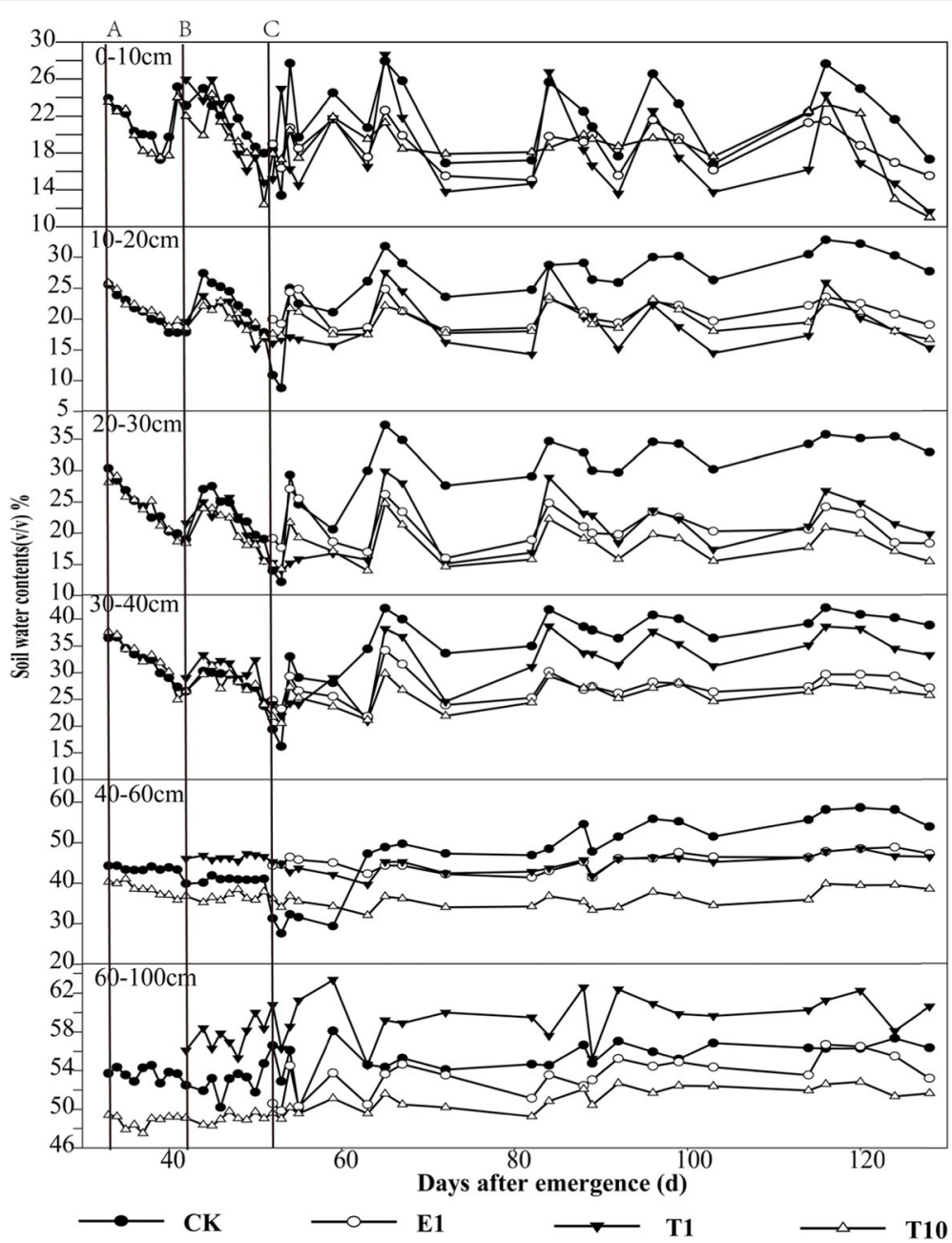

Fig. 3 Soil volume moisture content variation of different soil layer at 33-128 days after emergence in 2017 in various treatment groups: 1 and 10 days before the first irrigation ( $T 1, T 10$, respectively) and 1 day before the second irrigation (E1) after seedling emergence, with one control group of film mulching present across cotton plant growth stages (CK). A, B, and C represent removal of mulch on May 31, June 10, and June 20, 2017, i.e., 10 days, 1 day before the first irrigation, and one day before the second irrigation, respectively

flowering stages. As cotton reproduction proceeded, the gap in Y (II) values between the film-removal treatments and CK gradually narrowed (Fig. 5). In sum, in 2017, both the number of days after flowering and the timing of mulch removal significantly impacted Y (II). In 2016, only the latter had a significant impact on Y (II).

\section{Influence of mulch film removal on photochemical fluorescence quenching assuming interconnected PS-II antennae $(q L)$ and stern-Volmer type non-photochemical fluorescence quenching (NPQ)}

The qL (Fig. 6) value represents the level of electron transfer activity. In the year with more rainfall (2016), removing the plastic film significantly enhanced the $\mathrm{qL}$ of PS-II in the early stage of flowering ( 5 days postflowering), but earlier film-removal (T1 and T10 treatments) weakened electron transfer activity of PS-II in the later growth stage. The $\mathrm{qL}$ under the $\mathrm{E} 1$ treatment was strongest during the whole cotton growth period. In the normal rainfall year (2017), removal of the film promoted electron transfer activity of PS-II of XLZ42 earlier in the flowering (i.e., $1-15$ days post-flowering) but that of XLZ45 in mid- and later stages of flowering (i.e., 2545 days post-flowering). At 45 days after flowering, $\mathrm{qL}$ of PS-II in the T10 treatment was the highest.

In the late flowering stage (45 days post-flowering), among treatments, the NPQ (Fig. 6) of T10 was the lowest. However, in the early flowering stage, the NPQ of all three film-removal treatments exceeded that of CK in 2017, while the opposite occurred in 2016.

Different treatments, cotton varieties, and days after flowering had no significant influence on NPQ in 2016. Yet different treatments significantly affected $\mathrm{qL}$, in that there were significant differences between $\mathrm{E} 1$ or T10 and CK. In 

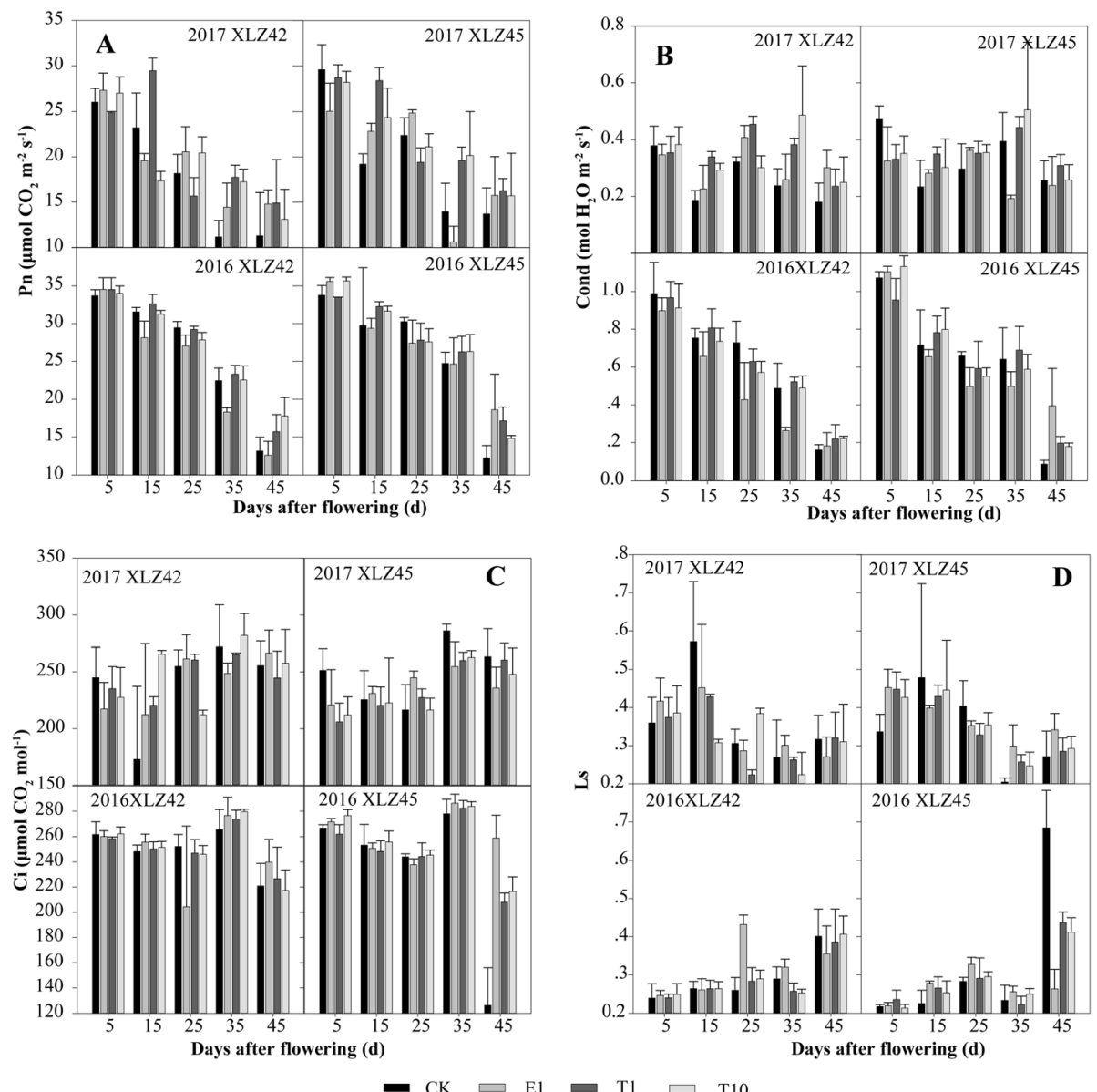

Fig. 4 Gas exchange parameters of cotton varieties (XLZ42 and XLZ45) at different days since flowering in various treatment groups: 1 (T1) and 10 days (T10) before the first irrigation, respectively, and 1 day before the second irrigation (E1) after seedling emergence during 2016-2017. The control group (CK) had film mulching throughout the growth stages. Bars are means \pm standard deviation $(n=3)$. Pn, photosynthetic rate; Cond, conductance to $\mathrm{H}_{2} \mathrm{O}$; $\mathrm{Ci}$, intercellular $\mathrm{CO} 2$ concentration; Ls, stoma limit value

Table 2 Correlation coefficients of net photosynthetic rate $(\mathrm{Pn})$ and other gas exchange parameters in various treatment groups: 1 and 10 days before the first irrigation (respectively $\mathrm{T} 1, \mathrm{~T} 10$ ) and 1 day before the second irrigation (E1) after seedling emergence during 2016-2017 ( $n=30)$

\begin{tabular}{|c|c|c|c|c|c|c|c|c|}
\hline Year & Treatment groups & Cond & $\mathrm{Ci}$ & Trmmol & WUE & WUEi & Ls & LUE \\
\hline \multirow[t]{4}{*}{2016} & CK & $0.926^{* *}$ & $0.433^{*}$ & $0.919^{* *}$ & 0.021 & $-0.654^{* *}$ & $-0.589^{* *}$ & $0.971^{* *}$ \\
\hline & E1 & $0.882^{* *}$ & -0.011 & $0.809^{* *}$ & 0.192 & $-0.461^{*}$ & -0.302 & $0.966^{* *}$ \\
\hline & $\mathrm{T} 1$ & $0.938^{* *}$ & $0.541^{* *}$ & $0.830^{* *}$ & 0.218 & $-0.855^{* *}$ & $-0.784^{* *}$ & $0.934^{* *}$ \\
\hline & $\mathrm{T} 10$ & $0.939^{* *}$ & $0.553^{* *}$ & $0.875^{* *}$ & 0.193 & $-0.872^{* *}$ & $-0.801^{* *}$ & $0.942^{* *}$ \\
\hline \multirow[t]{4}{*}{2017} & CK & $0.478^{* *}$ & -0.331 & $0.590^{* *}$ & $0.411^{*}$ & 0.305 & $0.358^{*}$ & $0.807^{* *}$ \\
\hline & E1 & $0.480^{* *}$ & $-0.516^{* *}$ & $0.655^{* *}$ & $0.449^{*}$ & $0.497^{* *}$ & $0.559^{* *}$ & $0.899^{* *}$ \\
\hline & $\mathrm{T} 1$ & 0.094 & $-0.768^{* *}$ & 0.283 & $0.775^{* *}$ & $0.801^{* *}$ & $0.825^{* *}$ & $0.889^{* *}$ \\
\hline & $\mathrm{T} 10$ & $0.432^{*}$ & $-0.453^{*}$ & $0.757^{* *}$ & $0.376^{*}$ & 0.328 & $0.423^{*}$ & $0.871^{* *}$ \\
\hline
\end{tabular}

Note: Pearson correlations were used. * Significant at the 0.05 probability level (two tailed). ${ }^{*}$ Significant at the 0.01 probability level (two tailed) Cond Conductance to $\mathrm{H}_{2} \mathrm{O}, \mathrm{Ci}$ Intercellular $\mathrm{CO}_{2}$ concentration, Trmmol Transpiration rate, WUE Water use efficiency, WUEi Intrinsic WUE, Ls Limiting value of stomata, LUE Light use efficiency 

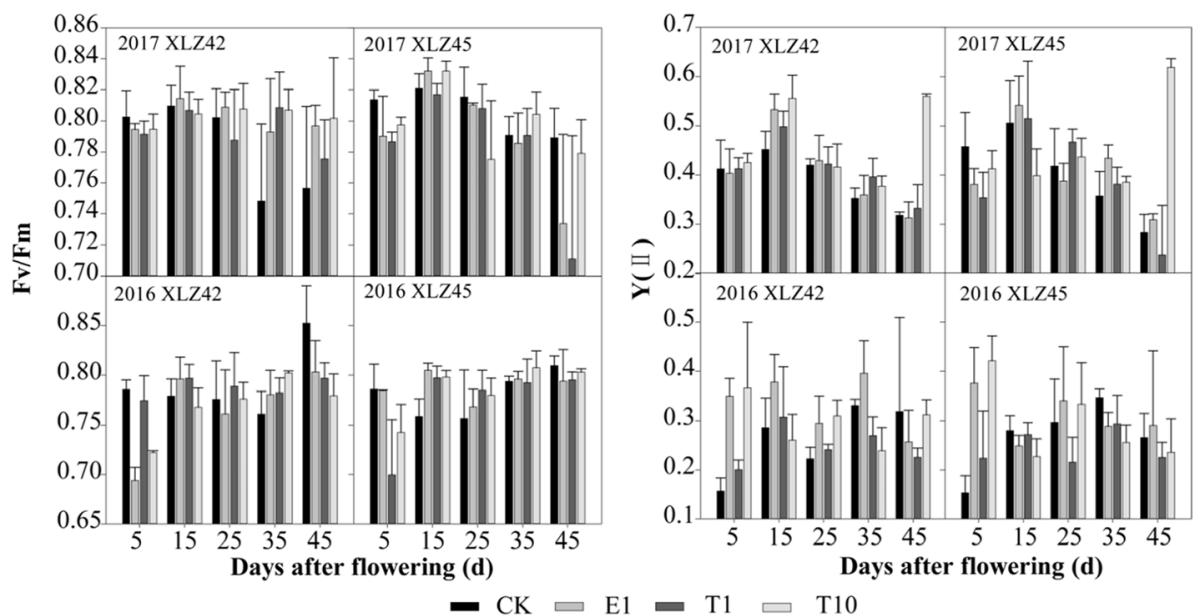

Fig. 5 Maximum photochemical quantum yield of PS-II (Fv/Fm) and actual photochemical quantum yield of PS-II (Y (II)) of cotton varieties (XLZ42 and XLZ45) at different days since flowering in various treatment groups: 1 and 10 days before the first irrigation (T1, T10, respectively) and 1 day before the second irrigation (E1) after seedling emergence, during 2016-2017. The control group (CK) had film mulching throughout the growth stages. Bars are means \pm standard deviation $(n=3)$

2017, only days after flowering had a significant impact on NPQ, and NPQ was similar among treatments. However, different treatments and days after flowering significantly influenced $\mathrm{qL}$, with that of T10 differing considerably from the other three film-removal treatments.

Influence of mulch film removal on the quantum yield of light-induced ( $Y(N P Q))$ and non-light induced( $Y(N O))$ nonphotochemical fluorescence quenching of cotton leaves At the early stage of flowering (5 days post-flowering), the values of $\mathrm{Y}$ (NPQ) (Fig. 7) of the three film-removal treatments in 2017 and the CK treatment in 2016 were greatest. This suggested cotton plants were stressed in each treatment and protected themselves by heat dissipation.

The Y (NO) value (Fig. 7) is an index of photic injury. In the early flowering stage, the film-removal treatment of XLZ42 (i.e., with the lower Y (NO) value), which tolerates the drought stress better (mainly via heat dissipation to avoid the photic injury), although XLZ45 (with the higher $\mathrm{Y}$ (NO) value) has poor drought tolerance, nonetheless it tried to protect itself from heat dissipation, but filmremoval treatment still received the photic injury. By

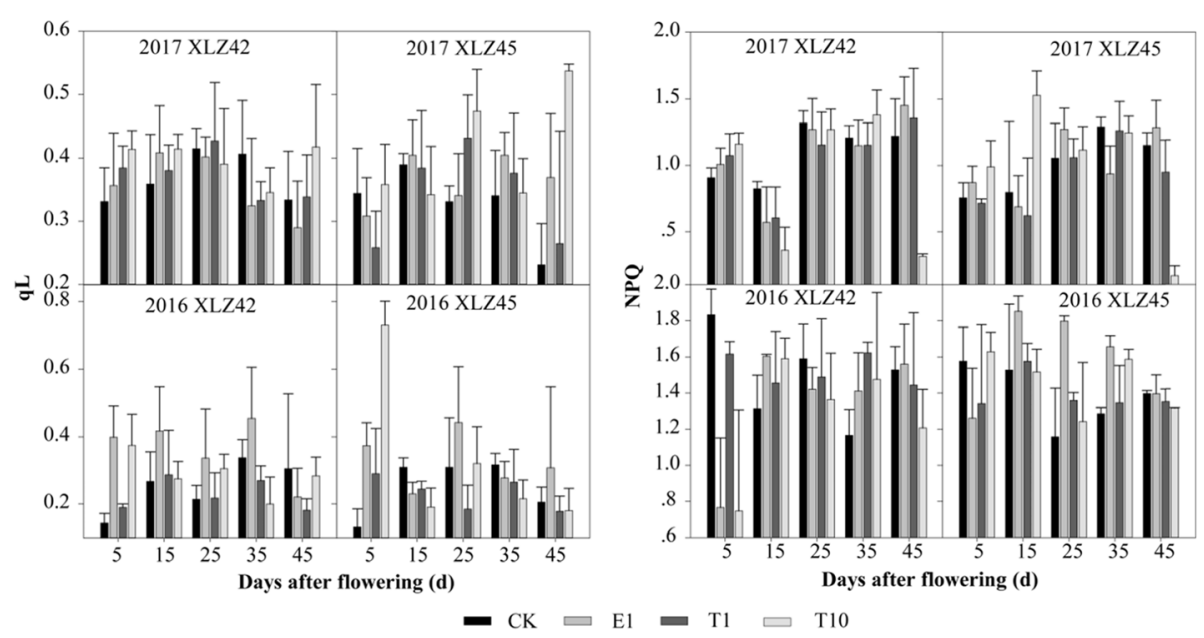

Fig. 6 Coefficient of photochemical fluorescence quenching assuming an interconnected PS-II antennae (qL) and Stern-Volmer type nonphotochemical fluorescence quenching (NPQ) of cotton varieties (XLZ42 and XLZ45), at different days since flowering in various treatment groups: 1 and 10 days before the first irrigation (T1,T10, respectively) and 1 day before the second irrigation (E1) after seedling emergence, during 2016-2017. The control group (CK) had film mulching throughout the growth stages. Bars are means \pm standard deviation $(n=3)$ 

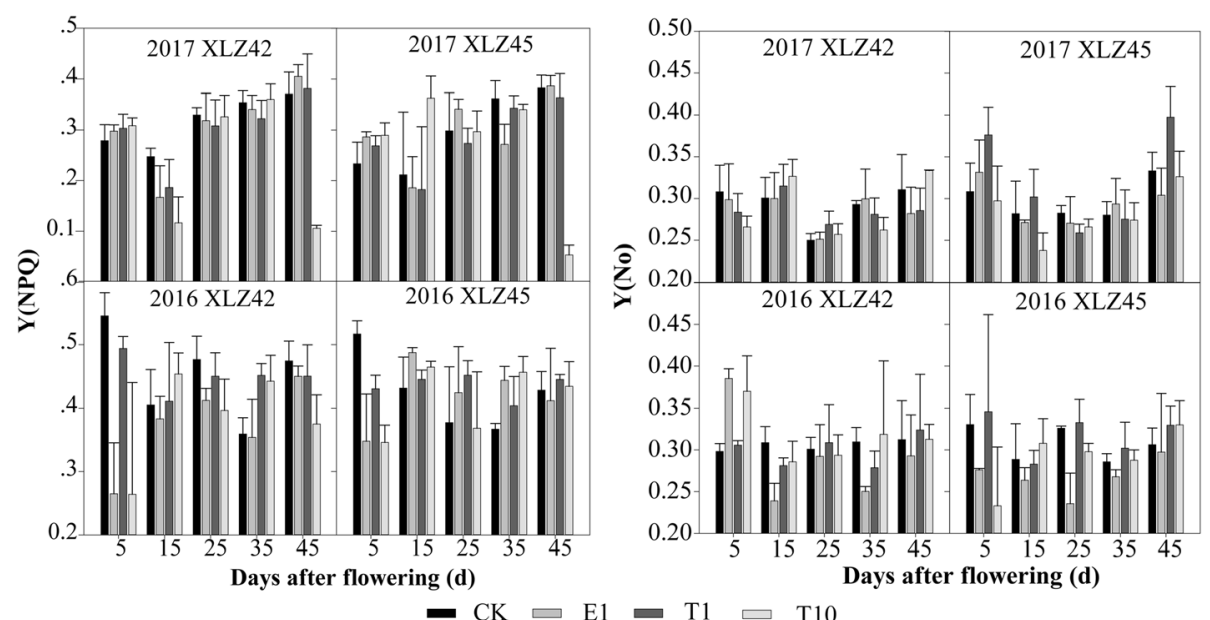

Fig. 7 Quantum yield of light-induced (Y (NPQ)) and non-light induced( $(\mathrm{NO}))$ non-photochemical fluorescence quenching of cotton varieties (XLZ42 and XLZ45) at different days since flowering in various treatment groups: 1 and 10 days before the first irrigation (T1, T10, respectively) and 1 day before the second irrigation (E1) after seedling emergence, during 2016-2017. The control group (CK) had film mulching throughout the growth stages. Bars are means \pm standard deviation $(n=3)$

contrast, in 2016 the lowest values of XLZ42 and XLZ45 were in the CK and T10 treatments, respectively. At the 45 days after flowering, T10 exhibited the lowest light protection capacity and the greatest photic injury. Multivariate analysis revealed that different treatments in 2016 and 2017 and days after flowering (2017) had a significant impact on Y (NPQ), while only days after flowering significantly affected $\mathrm{Y}(\mathrm{NO})$.

\section{Effects of mulch film removal on energy conversion of cotton leaves in different growth stages}

In 2017, except for the highest proportion of energy entering the photochemical process ( $\mathrm{P}$, the actual photochemical quantum yield of PS-II) in the T10 treatment of XLZ45 at 45 days after flowering, the $P$ value of other treatments showed a unimodal curve change, with the highest proportion occurring in the first 15 days since flowering. This indicated that in the normal year of rainfall, light energy absorbed at the early flowering stage is mainly shunted into photochemical reactions, but at the later flowering stage it mainly lost through thermal dissipation to avoid damage to cotton's photosynthetic mechanism. In 2016, the proportions of heat dissipation (D) under the four treatments were higher among years, changing little during the whole growth period. The $P$ value of $\mathrm{CK}$ at 5 days after flowering was significantly lower than those of other treatments. Thus further suggested that the activity of the PS-II photochemical reaction center of CK plants in their early flowering stage was lower in 2016 than that in 2017, with most excess light energy absorbed dissipated via heat dissipation and a few parts entering the photochemistry processes (Fig. 8)
At 45 days after flowering, the $P$ value of the T10 treatment was highest, and more obviously in 2017. This suggested that the earlier the film was removed, the sooner the drought stress, the more of which can increase the actual photochemical quantum yield of PS-II, making this trend is more obvious in the dry year (2015) performance of cotton.

\section{Rapid light curve of cotton leaf in different film-removal treatments at different days after flowering}

The rapid light curve directly conveys changes in the electron transfer activity of photoreaction system under different light intensity conditions. By fitting this curve to our data for cotton can be used to gauge the maximum electron transfer rate (ETRmax, Table 3), light energy utilization efficiency ( $\alpha$, Table 4$)$, and the tolerance degree to strong light (Ik, Table 5) of the plant's photoreaction system.

In the rainy year (2016), the removal of film improved both the ETR (Fig. 9) and ETRmax (Table 3) of cotton in all growth periods, especially in its early flowering stage. In the normal rainfall year (2017), however, it increased ETR (Fig. 9) and ETRmax (Table 3) in the mid flowering stage (15-25 days post-flowering). Film-removal treatments improved the light energy utilization efficiency in the early flowering stage but it was adversely affected in the mid flowering stage in the normal rainfall year (2017) (Table 4); in other plant growth periods it improved the light energy use efficiency of cotton (Table 3). The ability of plants to withstand strong light (Table 5) can be improved by removing the film at suitable periods, namely before the first irrigation in a rainy year, but before the second irrigation in normal rainfall years. 


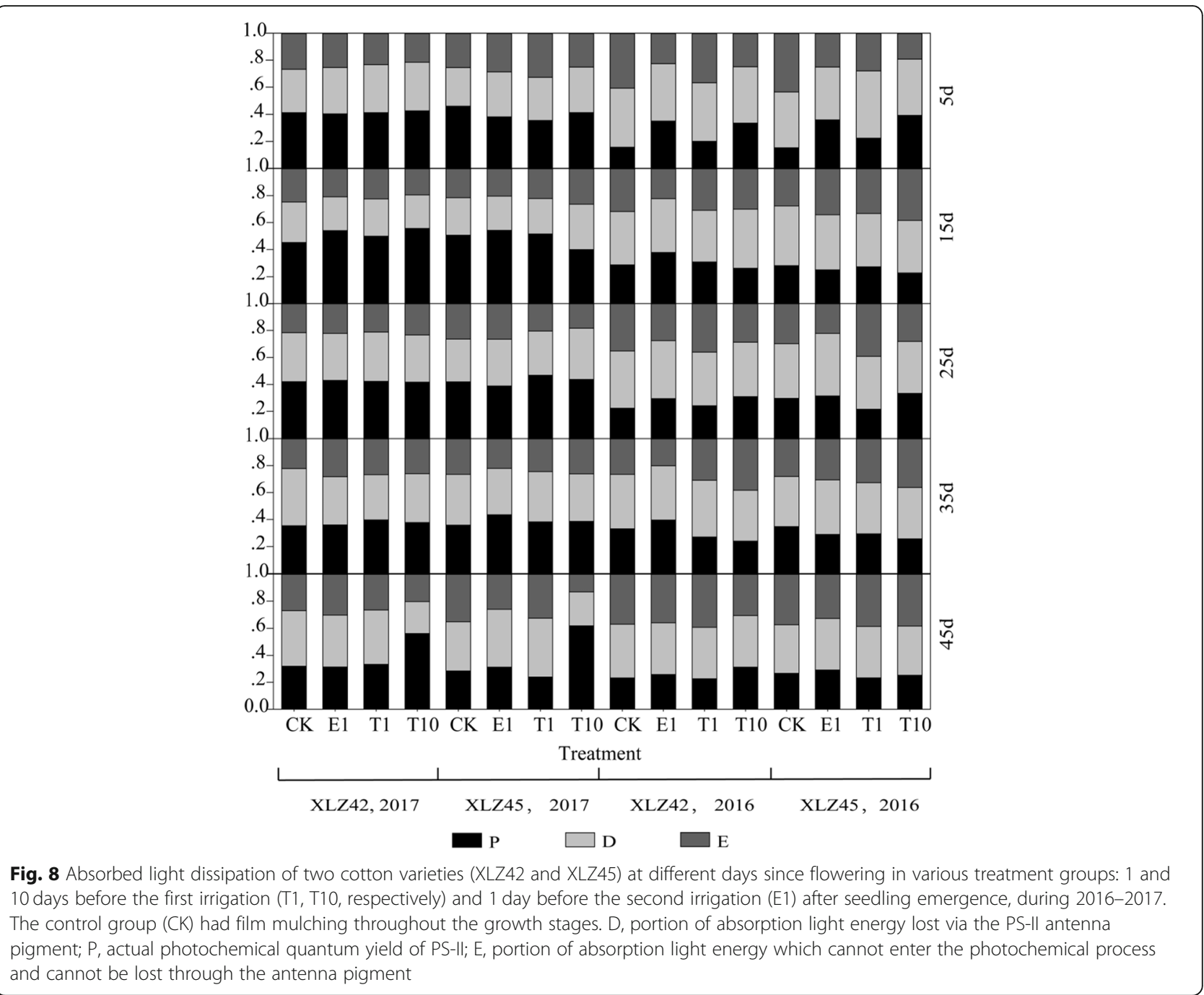

The MANOVA indicated that the number of days after flowering (2016/2017) (Table S2, S3) and different film-removal treatments (2016) (Table S2) had significant impacts on the ETRmax and Ik values of cotton, but in 2017 (Table S3) only days after flowering significantly influenced the $\alpha$ value.

\section{Population-level physiological parameters of cotton among film-removal treatments at different days since flowering}

As Fig. 10 shows, the leaf area index (LAI) of each treatment followed a unimodal curve of change. At the initial growth stage, leaf area increased most quickly, almost linearly. At different growth stages during the three years, the LAI of CK plants was generally the highest among treatments. Apart from the LAI of XLZ45 under the E1 treatment in 2017 (4.40) being highest, larger values were found in CK for both cotton varieties: 4.75 (XLZ42 in 2017), 6.42 (XLZ45 in 2016), 5.93 (XLZ42 in 2016), and 4.60 (XLZ42 in 2015). Higher LAIs of CK plants were beneficial for promoting their dry matter accumulation.

The trend in cotton dry matter accumulation in the film-removal treatments followed an S-shaped curve (Fig. 11). As cotton grew in size, its dry matter accumulation increased, but the rates of accumulation clearly varied among growth stages.

Table 6 showed that, in addition to 2015, all filmremoval treatments promoted dry matter accumulation and the maximum dry matter accumulation under the film-removal treatments were greatest overall. Specifically, Tmax appeared earlier with film removed than that in CK, as did the linear accumulation, while the linear accumulation time (t2-t1) was longer with a larger $\Delta \mathrm{W}_{\mathrm{t} 2^{-} \mathrm{t} 1}$ as well.

Yield and fiber quality of cotton among film-removal treatments The effect of removing the mulch film on yield was related to climatic conditions in different years. In the drought year (2015), it reduced the yield of cotton whereas increased the yield in other years. Fiber quality 
Table 3 Maximum electron transfer rate (ETRmax, $\mu \mathrm{mol} \cdot \mathrm{m}^{-2} \cdot \mathrm{s}^{-1}$ ) of two cotton varieties (XLZ42 and XLZ45) at different days after flowering in various treatment groups: Mulch film was removed at 1 and 10 days before the first irrigation (respectively T1(June 19, 2016 and June 10, 2017), T10(June 9, 2016 and May 31, 2017)) and 1 day before the second irrigation (E1(June 29, 2016 and June 20, 2017)) after seedling emergence, during 2016-2017. The control group (CK) had film mulching throughout the growth stages. Values are means \pm standard deviation $(n=3)$

\begin{tabular}{|c|c|c|c|c|c|c|c|}
\hline \multirow[t]{2}{*}{ Year } & \multirow[t]{2}{*}{ Varieties } & \multirow[t]{2}{*}{ Treatments } & \multicolumn{5}{|c|}{ Days after flowering /d } \\
\hline & & & 5 & 15 & 25 & 35 & 45 \\
\hline \multirow[t]{8}{*}{2017} & XLZ42 & CK & $112.80 \pm 13.49$ & $203.43 \pm 68.76$ & $350.87 \pm 102.40$ & $216.07 \pm 34.76$ & $158.63 \pm 30.01$ \\
\hline & & E1 & $114.10 \pm 12.65$ & $242.00 \pm 7.50$ & $273.80 \pm 57.09$ & $269.97 \pm 98.73$ & $163.37 \pm 28.63$ \\
\hline & & $\mathrm{T} 1$ & $133.70 \pm 31.40$ & $339.75 \pm 30.19$ & $312.80 \pm 31.68$ & $221.03 \pm 37.50$ & $175.90 \pm 12.85$ \\
\hline & & $\mathrm{T} 10$ & $142.27 \pm 12.95$ & $293.57 \pm 49.84$ & $315.50 \pm 3.38$ & $226.53 \pm 65.22$ & $153.80 \pm 43.27$ \\
\hline & XLZ45 & CK & $220.27 \pm 93.04$ & $202.70 \pm 66.08$ & $260.20 \pm 32.46$ & $244.67 \pm 72.55$ & $140.07 \pm 15.14$ \\
\hline & & E1 & $87.30 \pm 5.91$ & $261.17 \pm 54.77$ & $279.23 \pm 26.5$ & $262.30 \pm 35.13$ & $166.83 \pm 12.39$ \\
\hline & & $\mathrm{T} 1$ & $94.07 \pm 23.07$ & $223.90 \pm 69.86$ & $312.17 \pm 34.04$ & $254.07 \pm 66.68$ & $118.20 \pm 65.06$ \\
\hline & & $\mathrm{T} 10$ & $122.67 \pm 10.36$ & $360.77 \pm 96.89$ & $320.53 \pm 14.02$ & $209.70 \pm 28.74$ & $160.87 \pm 37.17$ \\
\hline \multirow[t]{8}{*}{2016} & XLZ42 & CK & $134.20 \pm 22.29$ & $209.40 \pm 12.87$ & $185.95 \pm 7.00$ & $258.90 \pm 7.35$ & $240.20 \pm 160.94$ \\
\hline & & E1 & $586.27 \pm 129.82$ & $561.13 \pm 352.30$ & $331.10 \pm 8.02$ & $294.40 \pm 22.88$ & $231.97 \pm 31.76$ \\
\hline & & $\mathrm{T} 1$ & $146.10 \pm 45.72$ & $365.37 \pm 180.43$ & $182.35 \pm 19.73$ & $223.55 \pm 5.87$ & $209.85 \pm 18.60$ \\
\hline & & $\mathrm{T} 10$ & $434.75 \pm 22.98$ & $375.33 \pm 176.71$ & $248.30 \pm 16.03$ & $204.15 \pm 25.39$ & $244.35 \pm 1.34$ \\
\hline & XLZ45 & CK & $151.97 \pm 7.60$ & $289.90 \pm 26.02$ & $254.90 \pm 30.21$ & $259.25 \pm 0.49$ & $220.85 \pm 15.49$ \\
\hline & & E1 & $381.60 \pm 77.64$ & $209.93 \pm 6.67$ & $243.90 \pm 35.50$ & $243.05 \pm 57.77$ & $304.75 \pm 10.25$ \\
\hline & & $\mathrm{T} 1$ & $222.53 \pm 51.70$ & $517.50 \pm 25.74$ & $207.60 \pm 25.81$ & $248.95 \pm 8.41$ & $197.90 \pm 31.68$ \\
\hline & & $\mathrm{T} 10$ & $475.33 \pm 197.34$ & $286.53 \pm 83.56$ & $307.40 \pm 26.02$ & $226.05 \pm 16.33$ & $195.20 \pm 64.06$ \\
\hline
\end{tabular}

Table 4 The initial slope of the fast light curve ( $a$, electrons photons ${ }^{-1}$ ) of two cotton varieties (XLZ42 and XLZ45) at different days after flowering in various treatment groups: Mulch film was removed at 1 and 10 days before the first irrigation (respectively T1(June 19, 2016 and June 10, 2017), T10(June 9, 2016 and May 31, 2017)) and 1 day before the second irrigation (E1(June 29, 2016 and June 20, 2017)) after seedling emergence, during 2016-2017. The control group (CK) had film mulching throughout the growth stages. Values are means \pm standard deviation $(n=3)$

\begin{tabular}{|c|c|c|c|c|c|c|c|}
\hline \multirow[t]{2}{*}{ Year } & \multirow[t]{2}{*}{ Varieties } & \multirow[t]{2}{*}{ Treatments } & \multicolumn{5}{|c|}{ Days after flowering /d } \\
\hline & & & 5 & 15 & 25 & 35 & 45 \\
\hline \multirow[t]{8}{*}{2017} & \multirow[t]{4}{*}{ XLZ42 } & CK & $0.22 \pm 0.01$ & $0.28 \pm 0.03$ & $0.30 \pm 0.01$ & $0.27 \pm 0.04$ & $0.28 \pm 0.02$ \\
\hline & & E1 & $0.27 \pm 0.06$ & $0.30 \pm 0.01$ & $0.29 \pm 0.01$ & $0.29 \pm 0.03$ & $0.28 \pm 0.00$ \\
\hline & & $\mathrm{T} 1$ & $0.25 \pm 0.04$ & $0.29 \pm 0.02$ & $0.23 \pm 0.02$ & $0.31 \pm 0.02$ & $0.28 \pm 0.01$ \\
\hline & & $\mathrm{T} 10$ & $0.28 \pm 0.01$ & $0.29 \pm 0.01$ & $0.28 \pm 0.01$ & $0.32 \pm 0.03$ & $0.32 \pm 0.02$ \\
\hline & \multirow[t]{4}{*}{ XLZ45 } & CK & $0.21 \pm 0.03$ & $0.25 \pm 0.04$ & $0.29 \pm 0.01$ & $0.29 \pm 0.03$ & $0.31 \pm 0.03$ \\
\hline & & E1 & $0.19 \pm 0.01$ & $0.30 \pm 0.00$ & $0.25 \pm 0.03$ & $0.26 \pm 0.02$ & $0.27 \pm 0.03$ \\
\hline & & $\mathrm{T} 1$ & $0.12 \pm 0.07$ & $0.32 \pm 0.00$ & $0.24 \pm 0.06$ & $0.30 \pm 0.04$ & $0.27 \pm 0.06$ \\
\hline & & $\mathrm{T} 10$ & $0.29 \pm 0.02$ & $0.25 \pm 0.01$ & $0.26 \pm 0.02$ & $0.31 \pm 0.02$ & $0.33 \pm 0.00$ \\
\hline \multirow[t]{8}{*}{2016} & \multirow[t]{4}{*}{ XLZ42 } & CK & $0.23 \pm 0.04$ & $0.25 \pm 0.02$ & $0.29 \pm 0.01$ & $0.26 \pm 0.02$ & $0.29 \pm 0.02$ \\
\hline & & E1 & $0.26 \pm 0.02$ & $0.25 \pm 0.01$ & $0.24 \pm 0.01$ & $0.23 \pm 0.01$ & $0.27 \pm 0.05$ \\
\hline & & $\mathrm{T} 1$ & $0.23 \pm 0.03$ & $0.29 \pm 0.05$ & $0.28 \pm 0.02$ & $0.24 \pm 0.02$ & $0.27 \pm 0.01$ \\
\hline & & $\mathrm{T} 10$ & $0.26 \pm 0.00$ & $0.28 \pm 0.01$ & $0.28 \pm 0.02$ & $0.26 \pm 0.01$ & $0.29 \pm 0.00$ \\
\hline & \multirow[t]{4}{*}{ XLZ45 } & CK & $0.26 \pm 0.02$ & $0.26 \pm 0.01$ & $0.27 \pm 0.01$ & $0.27 \pm 0.02$ & $0.29 \pm 0.00$ \\
\hline & & E1 & $0.30 \pm 0.02$ & $0.26 \pm 0.01$ & $0.24 \pm 0.01$ & $0.27 \pm 0.00$ & $0.27 \pm 0.00$ \\
\hline & & $\mathrm{T} 1$ & $0.27 \pm 0.07$ & $0.28 \pm 0.01$ & $0.27 \pm 0.01$ & $0.27 \pm 0.01$ & $0.29 \pm 0.04$ \\
\hline & & $\mathrm{T} 10$ & $0.28 \pm 0.01$ & $0.27 \pm 0.02$ & $0.26 \pm 0.01$ & $0.27 \pm 0.01$ & $0.30 \pm 0.01$ \\
\hline
\end{tabular}


Table 5 The minimum saturating irradiance $\left(\mathrm{I}, \mu \mathrm{mol} \mathrm{m} \mathrm{m}^{-2} \cdot \mathrm{s}^{-1}\right)$ of two cotton varieties $(\mathrm{XLZ42}$ and XLZ45) at different days after flowering in various treatment groups: Mulch film was removed at 1 and 10 days before the first irrigation (respectively T1(June 19, 2016 and June 10, 2017), T10(June 9, 2016 and May 31, 2017)) and 1 day before the second irrigation (E1 (June 29, 2016 and June 20, 2017)) after seedling emergence, during 2016-2017. The control group (CK) had film mulching throughout the growth stages. Values are means \pm standard deviation $(n=3)$

\begin{tabular}{|c|c|c|c|c|c|c|c|}
\hline \multirow[t]{2}{*}{ Year } & \multirow[t]{2}{*}{ Varieties } & \multirow[t]{2}{*}{ Treatments } & \multicolumn{5}{|c|}{ Days after flowering /d) } \\
\hline & & & 5 & 15 & 25 & 35 & 45 \\
\hline \multirow[t]{8}{*}{2017} & XLZ42 & CK & $510.67 \pm 65.80$ & $749.80 \pm 337.86$ & $1172.50 \pm 325.98$ & $829.47 \pm 201.06$ & $579.63 \pm 166.11$ \\
\hline & & E1 & $431.80 \pm 100.66$ & $821.00 \pm 48.93$ & $943.80 \pm 167.16$ & $960.87 \pm 401.76$ & $590.20 \pm 108.71$ \\
\hline & & $\mathrm{T} 1$ & $523.00 \pm 33.09$ & $1165.75 \pm 14.21$ & $1351.35 \pm 9.97$ & $711.43 \pm 92.12$ & $632.17 \pm 36.58$ \\
\hline & & $\mathrm{T} 10$ & $514.93 \pm 45.01$ & $1022.97 \pm 208.47$ & $1130.20 \pm 44.86$ & $725.07 \pm 252.24$ & $493.45 \pm 174.58$ \\
\hline & XLZ45 & CK & $1019.90 \pm 319.56$ & $800.50 \pm 197.89$ & $885.73 \pm 131.50$ & $860.73 \pm 293.51$ & $458.63 \pm 85.00$ \\
\hline & & E1 & $460.83 \pm 64.73$ & $884.40 \pm 189.65$ & $1133.30 \pm 217.56$ & $1001.27 \pm 198.83$ & $619.10 \pm 38.70$ \\
\hline & & $\mathrm{T} 1$ & $1324.60 \pm 1356.12$ & $709.20 \pm 232.78$ & $1361.77 \pm 496.88$ & $867.97 \pm 283.80$ & $456.87 \pm 302.19$ \\
\hline & & $\mathrm{T} 10$ & $420.97 \pm 22.18$ & $1455.90 \pm 364.75$ & $1213.97 \pm 118.44$ & $670.40 \pm 123.69$ & $489.37 \pm 109.52$ \\
\hline \multirow[t]{8}{*}{2016} & XLZ42 & CK & $612.40 \pm 40.79$ & $837.35 \pm 109.11$ & $640.80 \pm 42.43$ & $993.45 \pm 95.81$ & $854.00 \pm 627.91$ \\
\hline & & E1 & $2326.30 \pm 663.48$ & $2164.93 \pm 1232.72$ & $1398.40 \pm 120.35$ & $1285.87 \pm 119.02$ & $977.73 \pm 27.21$ \\
\hline & & $\mathrm{T} 1$ & $653.57 \pm 258.24$ & $1352.43 \pm 778.42$ & $653.15 \pm 116.46$ & $919.95 \pm 101.75$ & $786.25 \pm 38.68$ \\
\hline & & $\mathrm{T} 10$ & $1642.95 \pm 80.26$ & $1322.40 \pm 577.78$ & $902.20 \pm 56.03$ & $781.60 \pm 58.27$ & $849.45 \pm 6.43$ \\
\hline & XLZ45 & CK & $578.33 \pm 32.83$ & $1105.70 \pm 44.69$ & $959.50 \pm 56.21$ & $966.95 \pm 77.29$ & $767.25 \pm 48.72$ \\
\hline & & E1 & $1281.40 \pm 333.75$ & $808.73 \pm 38.04$ & $1011.65 \pm 86.9$ & $885.55 \pm 211.35$ & $1132.15 \pm 34.15$ \\
\hline & & $\mathrm{T} 1$ & $833.80 \pm 219.55$ & $1877.15 \pm 4.45$ & $774.70 \pm 42.35$ & $912.05 \pm 8.56$ & $708.40 \pm 209.87$ \\
\hline & & $\mathrm{T} 10$ & $1696.00 \pm 615.06$ & $1045.90 \pm 257.11$ & $1170.90 \pm 39.74$ & $832.25 \pm 106.42$ & $656.35 \pm 237.38$ \\
\hline
\end{tabular}

was also improved, albeit to a certain extent, and the earlier the film removal, the more pronounced was this trend. The lint yield and fiber quality showed no statistical difference between treatments (Table 7).

\section{Discussion \\ Influence of film-removal time on soil temperature, moisture, and cotton growth}

Film mulching mainly functions by increasing soil temperature and promoting plants' growth and development early in ontogeny (Braunack et al. 2015; Farrell and Gilliland 2011; O'Loughlin et al. 2015; Ramakrishna et al. 2006; Wang et al. 2016). Compared with uncovered soil of the cotton field, the temperature of film-covered soil increased by $1-3{ }^{\circ} \mathrm{C}$ from sowing time in spring to tasseling stages (Liu et al. 2014a, b; Su et al. 2011a); however, no significant differences in soil temperature between film-covered and film-removed groups were found for summer-sown sweet potatoes (Hou et al. 2015). In our study, we found the soil temperature increase by the mulching film could be maintained for ca. $50 \mathrm{~d}$. Within 50 d after cotton seedling emergence, film removal lowers soil temperature. From then on, the difference in soil temperature among layers between film-removal groups and CK narrowed: generally, with the film removed and the closer to the surface soil layer, the greater was the difference (Fig. 2).

As cotton grows, temperature becomes less of a dominant limiting factor, such that long-term film mulching can lead to excessive soil temperatures and poor soil permeability during late growth stages (Jiang 2011; Kwabiah 2005; Li et al. 2014a, b; Wang et al. 2009). This can interfere with root respiration, affecting plant development and leading to detrimental impacts on crop yield and quality (Jiang 2011; Kwabiah 2005; Li et al. 2014a, b; Wang et al. 2009). For a given species, removing the film from the ground at the appropriate growth stage could effectively reduce soil temperature, enhance root system activity, and optimize the distribution of photosynthetic products. Doing so would also help prevent crop prematurity and improve yield (AlAssir et al. 1991; Jiang et al. 2012; Kwon et al. 2011). This study showed that film-removal treatment increased the yield, with fiber quality also partly enhanced in the wet year (2016) (Table 7).

Mulching can reduce soil water consumption and increase water use efficiency, which is conducive to improved crop yields (Kader et al. 2017). However, some studies have shown that mulch can lead to increased water consumption of crops while promoting crop growth that need to absorb more water from 

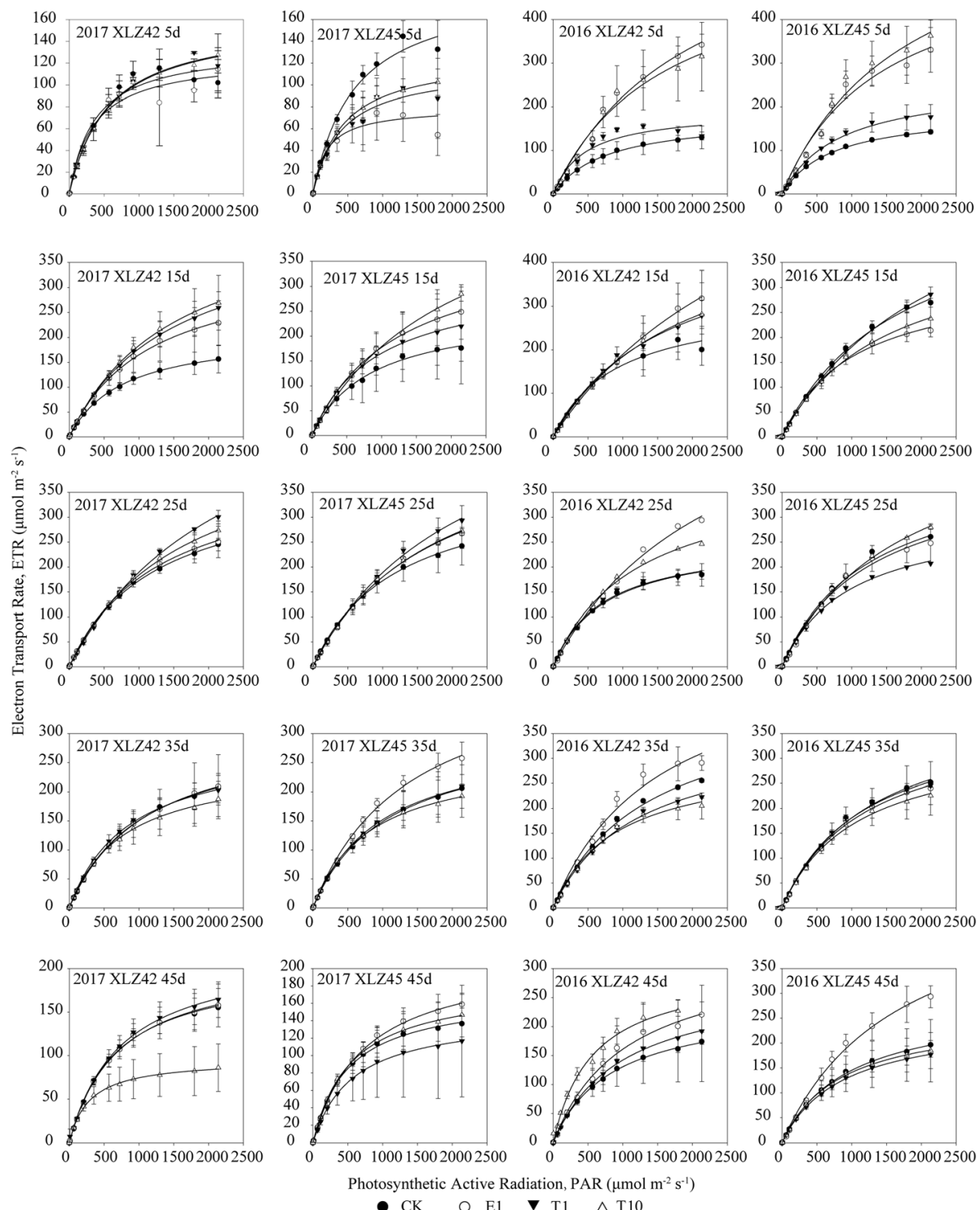

Fig. 9 Rapid light curves of two cotton varieties (XLZ42 and XLZ45) at different days since flowering in various treatment groups: 1 and 10 days before the first irrigation (respectively $T 1, T 10$ ) and 1 day before the second irrigation (E1) after seedling emergence, during 2016-2017. The control group (CK) had film mulching throughout the growth stages. Bars are means \pm standard deviation $(n=3)$

the deeper soil layers (Liu et al. 2014a, b), resulting in excessive water consumption in the deeper layers of the soil, which leading to reduced water storage in deep soil layers (Sun et al. 2014). Removal the mulching film could significantly reduce soil moisture content before cotton plants begin to flower ( $\mathrm{Li}$ et al. 2016; Zhang et al. 2016a, b), whereas no such effects occurred when it was applied after florescence ( $\mathrm{Li}$ et al. 2016). More than 20 years ago, Xia and Zhang (1994) showed that film removal before irrigation led to a soil moisture content of the 0-35 $\mathrm{cm}$ soil layer that was $18.2 \%$ lower, on average, up $30 \%$ lower than under constant mulching. Our study also indicated that, in 2017 , the $0-60 \mathrm{~cm}$ soil layer treated with mulch had a higher moisture content, but deeper soil $(60-100 \mathrm{~cm}$ layer $)$ under T1 treatment had the greatest moisture (Fig. 3). The reason for the above experimental results may be that film mulching can reduce the evaporation of soil moisture caused by direct sunlight, so the water content of $0-60 \mathrm{~cm}$ soil layer is higher. However, the growth of cotton under removing film treatment was not as vigorous as that under mulching film treatment, and the absorption of deep soil moisture was less, so the moisture content in $60-100 \mathrm{~cm}$ soil layer of removing film treatment is higher. 


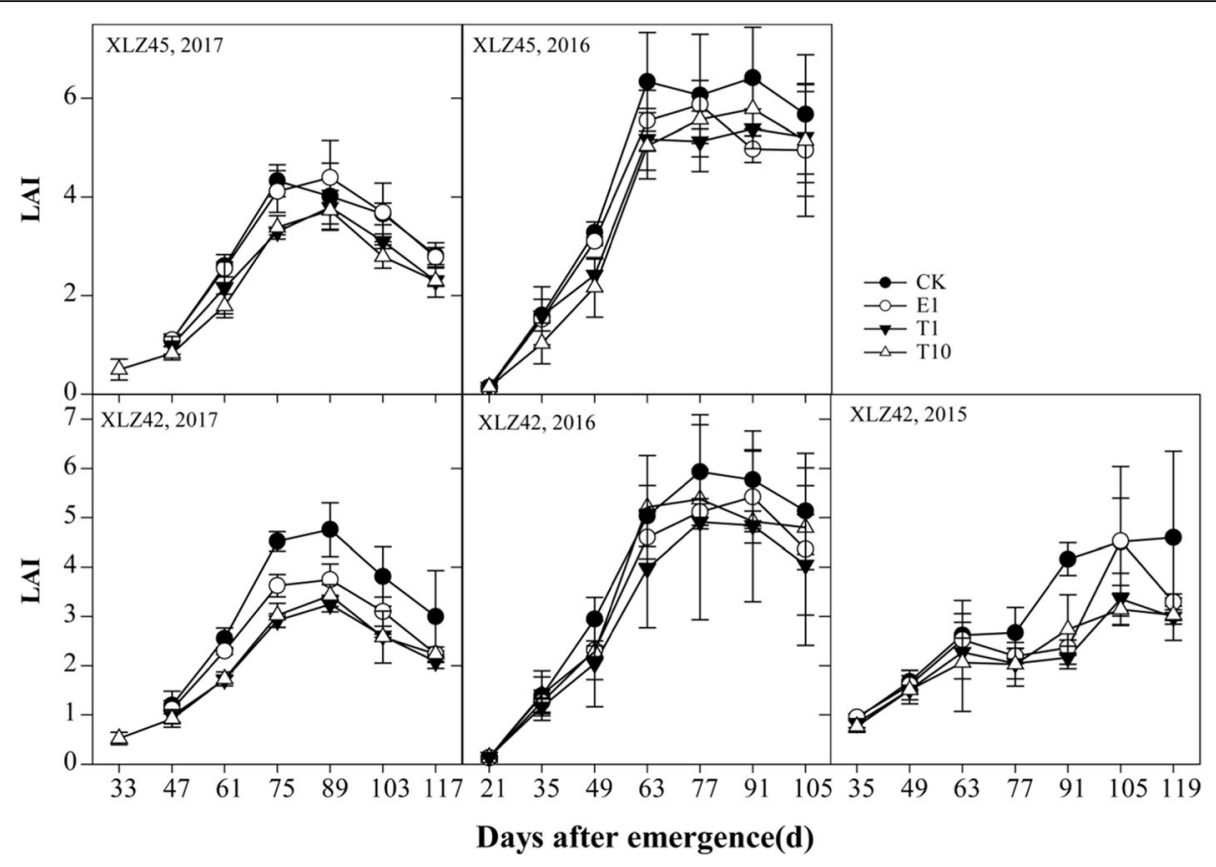

Fig. 10 Leaf area index (LAl) variation of two cotton varieties (XLZ42 and XLZ45) in various treatment groups: 1 and 10 days before the first irrigation (T1, T10, respectively) and 1 day before the second irrigation (E1) after seedling emergence, during 2015-2017. The control group (CK) had film mulching throughout the growth stages. Bars are means \pm standard deviation $(n=3)$

\section{Influence of film-removal timing on gas exchange parameters of cotton leaf}

In the early growth stage of cotton, mulching has watersaving and temperature-raising effects, which shortens the growing season of cotton. After starting to irrigate the cotton, with higher temperatures and irrigation amounts, continuous mulching may have adverse effects on the improved soil conditions, root development, and photosynthetic performance of targeted plants ( $\mathrm{Du}$ et al. 1989). Covering the soil with mulching film throughout
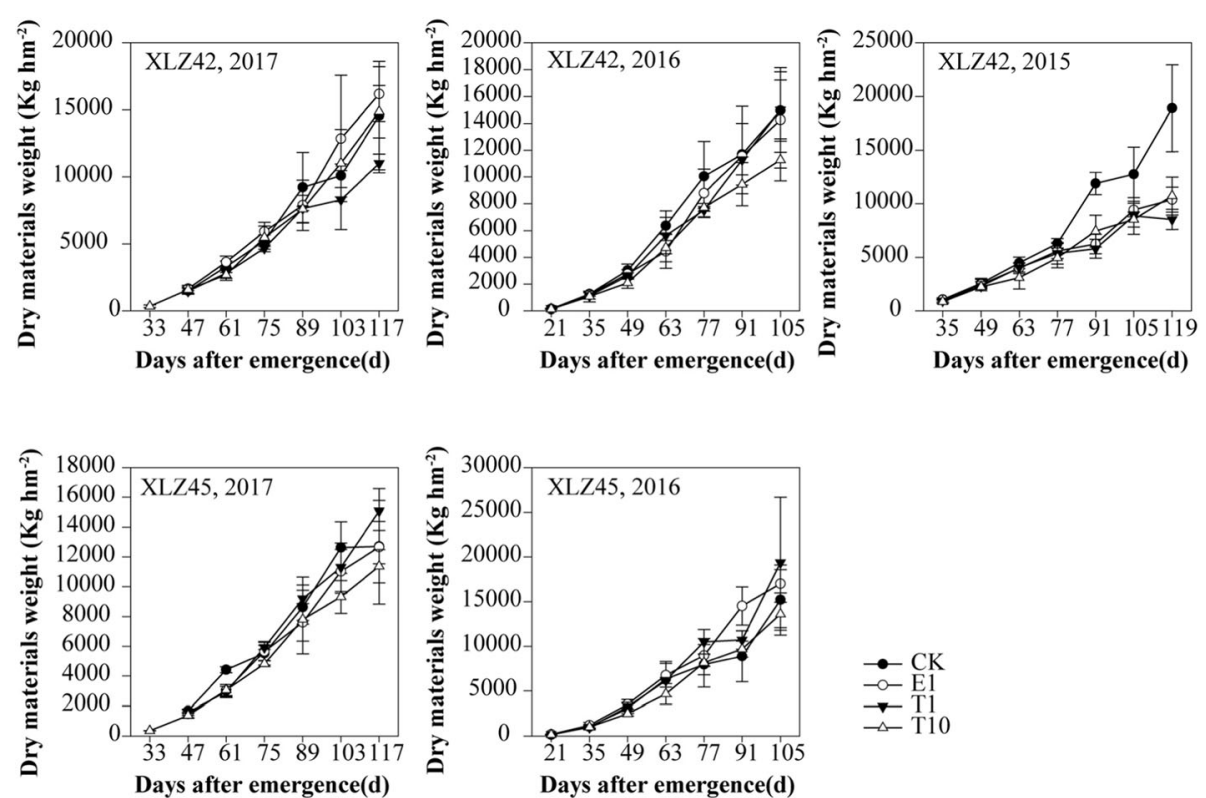

Fig. 11 Dry matter accumulation of two cotton varieties (XLZ42 and XLZ45) in various treatment groups: 1 and 10 days before the first irrigation ( $T 1, T 10$, respectively) and 1 day before the second irrigation (E1) after seedling emergence, during 2015-2017. The control group (CK) had film mulching throughout the growth stages. Bars are means \pm standard deviation $(n=3)$ 


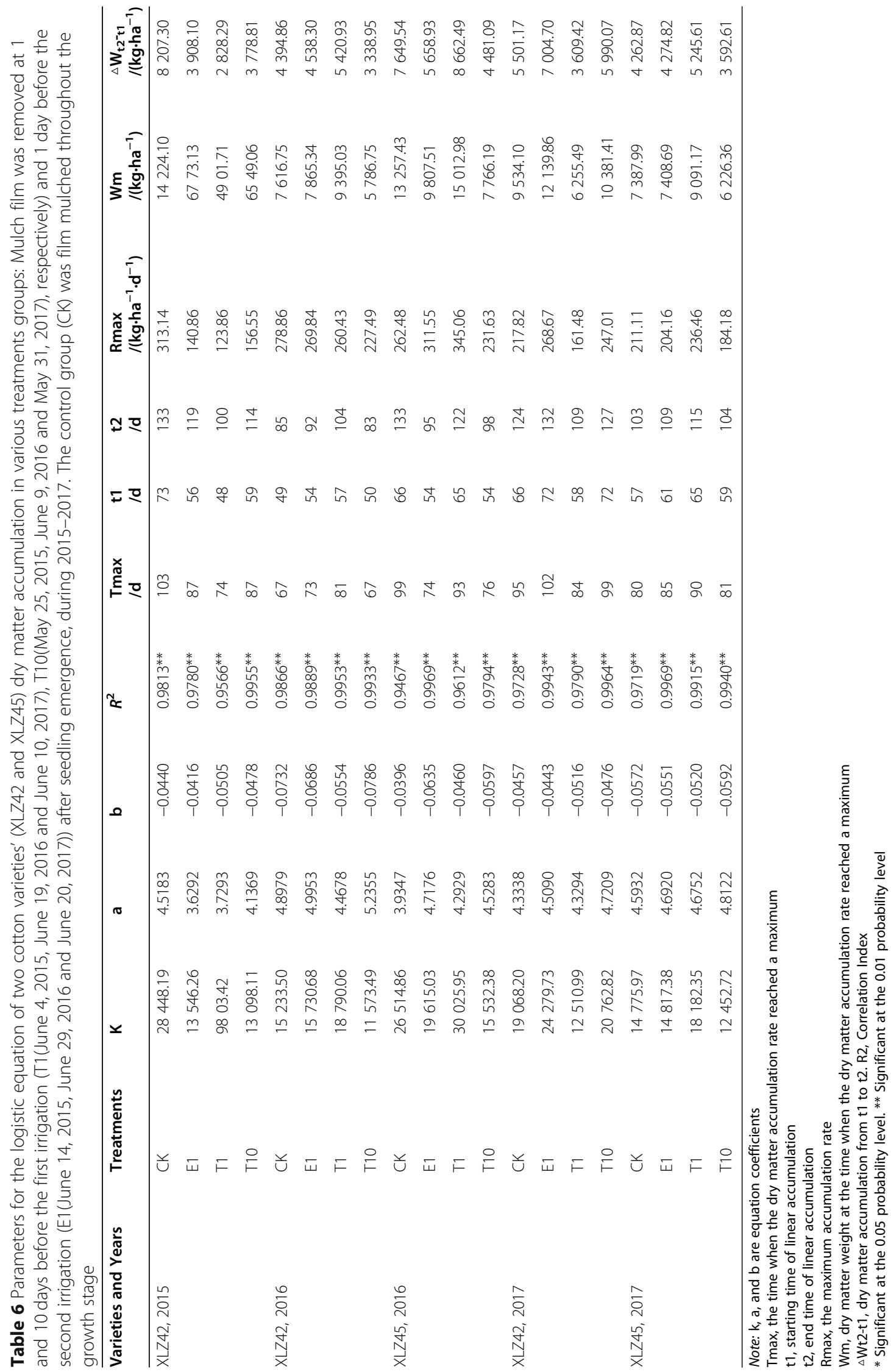




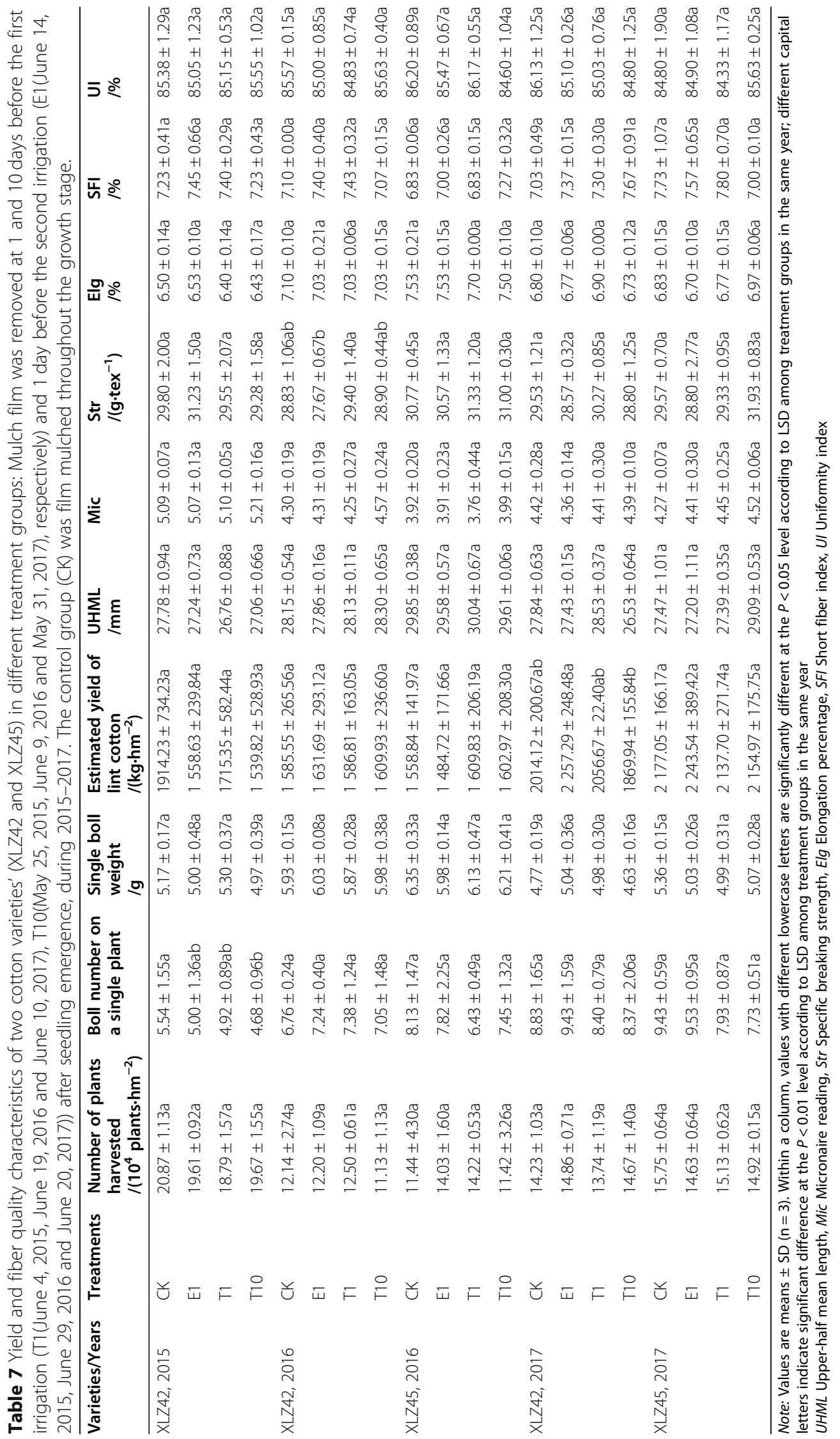


the growth period has been shown to cause rapid declines in net photosynthetic rate and chlorophyll content of tobacco (Wang et al. 2010; Yang et al. 2010), tomato (Wang et al. 2004), beet (Cai et al. 1988), cabbage (Zhang et al. 1995) and other crops, accelerating their diminished photosynthetic function in later growth stages. However, removal of mulch at the proper time improved photosynthetic functioning of both tobacco (Wang et al. 2010) and maize (He et al. 1999; Yu et al. 2006; Zhang et al. 2016a, b), which increased the accumulation of photosynthetic products, and alleviated the phenomenon of premature aging in these crop plants.

The results of our study also indicated that film removal could increase the Pn (Fig. 4a) in and Cond (Fig. 4b) in the late flowering stage. This may be because removing the mulch at later growth stages can create a favorable soil temperature and water environment and can promote photosynthesis.

\section{Influence of film-removal timing on chlorophyll fluorescence parameters of cotton leaves}

Chlorophyll fluorescence is closely related to each reaction in the process of photosynthesis, so how environmental change affects it may be shown by correlated changes in key fluorescence parameters (Chen et al. 2006). Just a few studies, from China and abroad, have investigated film-removal effects on chlorophyll fluorescence parameters at different growth stages. For example, the removal of mulching film at early growth stages caused different degrees of drought stress (Zhang et al. 2016a, b). In contrast to these, many studies (Boussadia et al. 2008; Mishra et al. 2012; Nankishore and Farrell 2016) worldwide have reported on how drought affects chlorophyll fluorescence parameters of crop plants.

Relevant studies have shown that Fv/Fm can be reliably used as a relative index for detecting droughtresistant crops (Mishra et al. 2012; Nankishore and Farrell 2016; Zhang et al. 2003), and it can quickly and accurately capture the water status of cotton leaves during drought stress (Xue et al. 2013). Under severe drought conditions, the $\mathrm{Fv} / \mathrm{Fm}$ values of leaves from cotton (Liu et al. 2008; Tang et al. 2007; Xie et al. 2015), Trigonella foenum-graecum (Baghbani-Arani et al. 2017), tulips (Miao et al. 2015), and olive trees (Boussadia et al. 2008) are known to decrease considerably. In this study, we found that film-removal treatment caused a severe drought stress on cotton in the early flowering stage, which led to the decrease of $\mathrm{Fv} / \mathrm{Fm}$ value (Fig. 5).

Mild drought is beneficial for increasing the opened proportion of the PS II reaction center, so more light energy is used to promote photosynthetic electron transport (Zhao et al. 2007), thereby improving the latter's ability. For example, ETR of Prunus persica
(L.) Batsch var. silver king was significantly improved after water stress induction (Osório et al. 2006). But the ETR of cotton (Deeba et al. 2012) decreases under severe drought conditions, and when its leaf water potential drops below -3Mpa, the ETR was reduced by more than $80 \%$ (Gleason et al. 2017). Earlier, Ogaya and Peñuelas (2003) had found that severe drought treatments caused a slight decrease in ETR values of both Quercus ilex and Phillyrea latifolia, whereas Snider et al. (2013) believe cotton's ETR is not affected by drought. Our results showed that removing the mulching film before irrigation in a rainy year (2016) could improve the ETR (Fig. 9) and the ETRmax (Table 3) by drought stress training, especially during the early flowering stage. But in a normal rainfall year (2017), film removal caused more severe drought and reduced ETR (Fig. 9) and ETRmax (Table 3) early in the flowering stage.

Under mild drought stress, the $\mathrm{Fv} / \mathrm{Fm}, \mathrm{Y}$ (II), and $\mathrm{qL}$ values of cotton plants can increase with prolonged stress (Xu et al. 2017). Drought stress also increased the NPQ of cotton (Liu et al. 2008) and olive (Boussadia et al. 2008) plants, and also decreased the $\mathrm{qL}$ value of rice (Pieters and Souki 2005).

Here, we found the $\mathrm{Fv} / \mathrm{Fm}$ value of cotton under the film-removal treatments was generally higher after the hardening of certain drought stress in the mid-stage of flowering (Fig. 5). Removing the film improved the Y (II) values (Fig. 5) in the mid flowering stage in 2017 (i.e., 15 to 45 days since flowering). In 2017, the NPQ of film-removal treatments was higher than $\mathrm{CK}$ at the early flowering stage (Fig. 6). Our results suggest film removal can increase the $\mathrm{qL}$ value of cotton in rainy years, but in normal rainfall years, it would increase drought-resistant varieties' $\mathrm{qL}$ value. In the late flowering stage, the $\mathrm{qL}$ value of film-removal treatments was reduced in the years with heavy rainfall, while the opposite likely occurs true in years with normal rainfall.

\section{Conclusion}

To improve soil temperature and conserve soil moisture content in cotton plants, this effect of film mulching should be maintained for at least 50 days after seedlings emerge. Removing the film before this will seriously affect cotton growth and development. The benefits of timed removal of the film, whether before the first or second irrigation after emergence, should be decided according to the climate of a given year. It is beneficial for promoting photosynthesis in the late flowering stage of cotton after early drought stress induction, and increasing the cotton yield and fiber quality to a certain extent, but no significant difference was reached. 


\section{Abbreviations}

$\triangle$ Wt2-t1: Dry matter accumulation from t1 to t2; Ca: Atmospheric $\mathrm{CO}_{2}$ concentration; $\mathrm{Ci}$ : Intercellular $\mathrm{CO}_{2}$ concentration; Cond: Conductance to $\mathrm{H}_{2} \mathrm{O}$; D: Portion of absorption light energy lost via the PS-II antenna pigment; E: Portion of absorption light energy which cannot enter the photochemical process and cannot be lost through the antenna pigment; Elg: Elongation percentage; ETR: Actual electron transport rate; ETRmax: Maximum electron transfer rate; F': Fluorescence at any time; FO: Original fluorescence; FO': Minimal fluorescence at light adaptation; Fm: Maximal fluorescence; Fm ': Maximal Fluorescence at light adaptation; FV/Fm: The maximum photochemical quantum yield of PS-II; GLM: General linear model; Ik: The minimum saturating irradiance (corresponding to plant tolerance of intense light); LAl: Leaf area index; Ls: The stoma limit value; LUE: Light use efficiency; MANOVA: Multi-factor analysis of variance; Mic: Micronaire reading; NPQ: The Stern-Volmer type non-photochemical fluorescence quenching: P: Actual photochemical quantum yield of PS-II; PAR: Photosynthetic active radiation; Pn: Photosynthetic rate; PS-II: Photoreaction system II; qL: The coefficient of photochemical fluorescence quenching, assuming interconnected PS II antennae and lake model; $R^{2}$ : Correlation Index; rETR: The relative electron transfer rate; $R_{\max }$ : The maximum accumulation rate; SFI: Short fiber index; Str: Specific breaking strength; $\mathrm{t} 1$ : Starting time of linear accumulation; t2: End time of linear accumulation; $T_{\max }$ : The time when the dry matter accumulation rate reached a maximum; UHML: Upper-half mean length; UI: Uniformity index; $W_{m}$ : Dry matter weight at the time when the dry matter accumulation rate reached a maximum; WUE: Water use efficiency; WUEi: Intrinsic WUE; Y (II): The actual photochemical quantum yield of PS-II; Y (NO): The quantum yield of non-light-induced non-photochemical fluorescence quenching; $Y(\mathrm{NPQ})$ : The quantum yield of light-induced (i.e., $\Delta \mathrm{pH}$ and zeaxanthin-dependent) non-photochemical fluorescence quenching; a: An initial slope of the fast light curve (conveying the efficiency of light energy utilization).

\section{Supplementary Information}

The online version contains supplementary material available at https://doi. org/10.1186/s42397-021-00091-7.

Additional file 1: Table S1. F-value of MANOVA of the gas exchange parameters in 2016 and 2017. Table S2. F-value of MANOVA of the chlorophyll fluorescence parameters in 2016. Table S3. F-value of MANOVA of the chlorophyll fluorescence parameters in 2017.

\section{Acknowledgments}

We extend our gratitude to Mr. Wang, Jin for providing us with the meteorological data.

\section{Authors' contributions}

Yang XK designed the study, Zhang ZQ wrote the main manuscript text and prepared all figures. Zhang L, Tian HY, and Niu Y carried out the experimental work and ananlyzed the data. All authors read and approved the final manuscript.

\section{Funding}

This study was supported financially by the special fund for scientific research into non-profit industries (agriculture; grant no. 201503120).

\section{Availability of data and materials}

The datasets used and analyzed during the current study are available from the corresponding author on reasonable request.

\section{Declarations}

Ethics approval and consent to participate

Not applicable.

\section{Consent for publication}

Not applicable.

\section{Competing interests}

The authors declare that they have no competing interests.

\section{Author details}

'Xinjiang Academy of Agricultural and Reclamation Science, Shihezi, Xinjiang, China 832000. ${ }^{2}$ Key Laboratory of Xinjiang Production and Construction Corps for Cereal Quality Research and Genetic Improvement, Shihezi, Xinjiang, China 832000. '3 Shihezi University, Shihezi, Xinjiang, China 832000.

Received: 3 December 2020 Accepted: 25 April 2021

Published online: 08 June 2021

\section{References}

Adhikari R, Bristow KL, Casey PS, et al. Preformed and sprayable polymeric mulch film to improve agricultural water use efficiency. Agri Water Manage. 2016; 169:1-13. https://doi.org/10.1016/j.agwat.2016.02.006.

Al-Assir IA, Rubeiz IG, Khoury RY. Response of fall greenhouse COS lettuce to clear mulch and nitrogen fertilizer. J Plant Nutr. 1991;14(10):1017-22. https:// doi.org/10.1080/01904169109364261.

Andersson S, Nilsson SI. Influence of pH and temperature on microbial activity, substrate availability of soil-solution bacteria and leaching of dissolved organic carbon in a mor humus. Soil Biol Biochem. 2001;33:1181-91. https:// doi.org/10.1016/S0038-0717(01)00022-0.

Baghbani-Arani A, Modarres-Sanavy SAM, Mashhadi-Akbar-Boojar M, MokhtassiBidgoli A. Towards improving the agronomic performance, chlorophyll fluorescence parameters and igments in fenugreek using zeolite and vermicompost under deficit water stress. Ind Crop Prod. 2017;15:346-57. https://doi.org/10.1016/j.indcrop.2017.08.049.

Bai J, Wang J, Chen $X$, et al. Seasonal and inter-annual variations in carbon fluxes and evapotranspiration over cotton field under drip irrigation with plastic mulch in an arid region of Northwest China. J Arid Land. 2015;7(2):272-84. https://doi.org/10.1007/s40333-014-0012-x.

Berry JA, Downton WJS. Environmental regulation of photosynthesis. In: Govindjee editor. Photosynthesis (Vol II). New York: Academic; 1982. p. 263343. https://doi.org/10.1016/B978-0-12-294302-7.50017-3.

Bilger W, Björkman O. Role of the xanthophylls cycle in photoprotection elucidated by measurements of light-induced absorbance changes, fluorescence and photosynthesis in Hedera canariensis. Photosynth Res. 1990;25(3):173-85. https://doi.org/10.1007/BF00033159.

Boussadia O, Mariem FB, Mechri B, et al. Response to drought of two olive tree cultivars (cv Koroneki and Meski). Sci Hortic. 2008;116:388-93.https://doi. org/10.1016/j.scienta.2008.02.016.

Braunack MV, Johnston DB, Price J, Gauthier E. Soil temperature and soil water potential under thin oxodegradable plastic film impact on cotton crop establishment and yield. Field Crop Res. 2015;184:91-103. https://doi.org/10.1 016/j.fcr.2015.09.009.

Cai B, Xiao ZQ, Bai DC. The present and prospect of study on sugarbeet plastic mulching cultivated technique in our country. China Sugarbeet. 1988;3:12-7.

Chen JM, Yu XP, Cheng JA. The application of chlorophyll fluorescence kinetics in the study of physiological responses of plants to environmental stresses. Acta Agriculturae Zhejiangensis. 2006;18(1):51-5.

Chen JS. Characteristics of soil temperature and soil water for winter wheat with no-tillage and effect on winter wheat growth in North China plain. Ph. D. Thesis. Beijing: China Agric Univ; 2005. (in Chinese with English abstract)

Deeba F, Pandey AK, Ranjan S, et al. Physiological and proteomic responses of cotton (Gossypium herbaceum L.) to drought stress. Plant Physiol Biochem. 2012;53:6-18. https://doi.org/10.1016/j.plaphy.2012.01.002.

Dong HG, Liu T, Li YG. Effects of plastic film residue on cotton yield and soil physical and chemical properties in Xinjiang. Transact Chin Soc Agric Eng. 2013;29:91-9(in Chinese with English abstract). https://doi.org/10.3969/j.issn.1 002-6819.2013.08.011.

Du CY, Yuan ZX, Jin Y. The effect of removing mulch is better for corn in the case of mulch film. Modern Agri. 1989;10:13. https://doi.org/10.14070/j.cnki.1 5-1098.1989.10.012.

Eilers PHC, Peeters JCH. A model for the relationship between light intensity and the rate of photosynthesis in phytoplankton[J]. Ecol Model. 1988:42:199-215. https://doi.org/10.1016/0304-3800(88)90057-9.

Farrell AD, Gilliland TJ. Yield and quality of forage maize grown under marginal climatic conditions in northern Ireland. Grass Forage Sci. 2011;66(2):214-23. https://doi.org/10.1111/j.1365-2494.2010.00778.x.

Genty B, Briantais JM, Baker NR. The relationship between the quantum yield of photosynthetic electron transport and quenching of chlorophyll fluorescence. Biochim Biophys Acta Gen Subj. 1989;990(1):87-92. https://doi. org/10.1016/S0304-4165(89)80016-9. 
Gleason SM, Wiggans DR, Bliss CA, Comas LH. Coordinated decline in photosynthesis and hydraulic conductance during drought stress in Zea mays. Flora. 2017;227:1-9. https://doi.org/10.1016/j.flora.2016.11.017.

He RX, Wang YG, Zhao JY. The effect of different growth period uncovering membrane in dry land on corn physiological properties and yields. J Shanx Agric Univ. 1999;1:19-21, 31, 92-93. https://doi.org/10.13842/j.cnki.issn16718151.1999.01.006.

Hou F, Zhang L, Xie B, et al. Effect of plastic mulching on the photosynthetic capacity, endogenous hormones and root yield of summer-sown sweet potato (Ipomoea batatas (L). Lam.) in northern China. Acta Physiol Plant. 2015;37(164):1-10. https://doi.org/10.1007/s11738-015-1912-x.

Hu XT, Li MS. Effect of trickle irrigation under sub-film on the soil conditions of rhizosphere in cotton. Chin J Eco-Agric. 2003;11:121-3 (in Chinese with English abstract)

Jian GL, Zhang YJ, Lu MG, et al. Tons of cotton-a new thought of super high yield of cotton in China. High-Technol Industrial. 2007;11:90-1 (in Chinese with English abstract).

Jiang GM, Li YN, Liu F, et al. Effects of soil moisture level and film mulch removal period on water use efficiency and physiological properties of maize (Zea mays L.). J Food Agric Environ. 2012;10(3\&4):695-700.

Jiang WH. Study on growth and yield of film-mulched flue-cured tobacco under different irrigation amounts. Ms thesis. China: Northwest A\&F Univ; 2011 (in Chinese with English abstract)

Kader MA, Senge M, Mojid MA, Nakamura K. Mulching type-induced soil moisture and temperature regimes and water use efficiency of soybean under rain-fed condition in Central Japan. Int Soil Water Conserv Res. 2017; 5(4):302-8. https://doi.org/10.1016/j.iswcr.2017.08.001.

Kitajima M, Butler WL. Quenching of chlorophyll fluorescence and primary photochemistry in chloroplasts by dibromothymoquinone. Biochimica et Biophysica Acta (BBA) - Bioenergetics. 1975;376(1):105-15. https://doi.org/1 0.1016/0005-2728(75)90209-1.

Kramer DM, Johnson G, Kiirats O, Edwards GE. New fluorescence parameters for the determination of QA redox state and excitation energy fluxes. Photosynth Res. 2004;79(2):209-18. https://doi.org/10.1023/B:PRES.00000153 91.99477.0d.

Kwabiah AB. Growth, maturity, and yield responses of silage maize (Zea mays L.) to hybrid, planting date and plastic mulch. J New Seeds. 2005;7(2):37-59. https://doi.org/10.1300/J153v07n0203.

Kwon KS, Azad MOK, Hwang JM. Mulching methods and removing dates of mulch affects growth and post harvest quality of garlic (Allium sativum L.) CV. Uiseong. Kor J Hort Sci Technol. 2011;29(4):293-7.

Li FM, Wang J, Xu JZ, Xu HL. Productivity and soil response to plastic film mulching durations for spring wheat on entisols in the semiarid loess plateau of China. Soil Tillage Res. 2014a;78(1):9-20. https://doi.org/10.1016/j. still.2003.12.009.

Li J, LV J, Liu XW, et al. Effect of different uncovering plastic film periods on water use efficiency, soil salinity and yield of cotton. Acta Agriculturae BorealiOccidentalis Sinica. 2016;25(9):1327-32. https://doi.org/10.7606/j.issn.1004-13 89.2016.09.008

Li P, Zhang YJ, Liu LT, et al. Effects of water stress on water utilization and leaf photosynthetic characteristics in cotton (Gossypium hirsutum L.) seedlings. Cotton Sci. 2014b;26(2):113-21.

Li SX, Zhang ZQ, Wei JJ. The effects of different ways of mulching film on cotton development. Xinjiang Agric Sci. 2010;47:1218-23 (in Chinese with English abstract).

Li YQ. Effect of plastic film residue on transportation of water and nitrate and seedling root of crops. Beijing: Chinese Academy of Agricultural Sciences; 2016 (in Chinese with English abstract).

Liu RX, Wang YH, Chen BL, et al. Effects of nitrogen levels on photosynthesis and chlorophyll fluorescence characteristics under drought stress in cotton flowering and boll-forming stage. Acta Agron Sin. 2008;34(4):675-83. https:// doi.org/10.3724/SP.J.1006.2008.00675

Liu SY, Li ZH, Zhang LF, et al. Effect of plastic film mulching on absorption and distribution of $\mathrm{P}$ and $\mathrm{K}$ and water use efficiency of spring maize in North China plain. J Soil Water Conserv. 2014a;28(4):97-103. https://doi.org/10.13 870/j.cnki.stbcxb.2014.04.018.

Liu SY, Zang LF, Li ZH, et al. Effects of plastic mulch on soil moisture and temperature and limiting factors to yield increase for dryland spring maize in the North China. Chin J Appl Ecol. 2014b;25(11):3197-206(in Chinese with English abstract). https://doi.org/10.13287/j.1001-9332.20140829.001.
Malone S, Herbert DA, Holshouser DL. Evaluation of the LAI-2000 plant canopy analyzer to estimate leaf area in manually defoliated soybean. Agron J. 2002; 94(5):1012-9. https://doi.org/10.2134/agronj2002.1012.

Miao Y, Zhu Z, Guo Q, Ma H, Zhu L. Alternate wetting and drying irrigationmediated changes in the growth, photosynthesis and yield of the medicinal plant Tulipa edulis. Ind Crop Prod. 2015;66:81-8. https://doi.org/10.1016/j. indcrop.2014.12.002.

Ming DX. Advanced biostatistics. Beijing: China Agric Press; 2006 (in Chinese).

Mishra KB, lannacone R, Petrozza A, et al. Engineered drought tolerance in tomato plants is reflected in chlorophyll fluorescence emission. Plant Sci. 2012;182:79-86. https://doi.org/10.1016/j.plantsci.2011.03.022.

Nabi G, Mullins CE. Soil temperature dependent growth of cotton seedlings before emergence. Pedosphere. 2008;18(1):54-9. https://doi.org/10.1016/S1 002-0160(07)60102-7.

Nankishore A, Farrell AD. The response of contrasting tomato genotypes to combined heat and drought stress. J Plant Physiol. 2016;202:75-82. https:// doi.org/10.1016/j.jplph.2016.07.006.

Nkwachukwu Ol, Chima CH, Ikenna AO, Albert L. Focus on potential environmental issues on plastic world towards a sustainable plastic recycling in developing countries. Int J Ind Chem. 2013;4(1):34-46. https://doi.org/1 0.1186/2228-5547-4-34.

Ogaya R, Peñuelas J. Comparative field study of Quercus ilex and Phillyrea latifolia: photosynthetic response to experimental drought conditions. Environ Exp Bot. 2003;50(2):137-48. https://doi.org/10.1016/S0098-8472(03)00019-4.

O'Loughlin J, Finnan J, Mcdonnel K, et al. Improving early growth in Miscanthusxgiganteus crops by the application of plastic mulch film. Asp Appl Biol. 2015;131:217-21.

Osório ML, Breia E, Rodrigues A, et al. Limitations to carbon assimilation by mild drought in nectarine trees growing under field conditions. Environ Exp Bot. 2006;55(3):235-47. https://doi.org/10.1016/j.envexpbot.2004.11.003.

Peñuelas J, Filella I, Llusia J, et al. Comparative field study of spring and summer leaf gas exchange and photobiology of the Mediterranean trees Quercus ilex and Phillyrea latifolia. J Exp Bot. 1998;49(319):229-38. https://doi.org/10.1093/ jexbot/49.319.229.

Pieters AJ, Souki SE. Effects of drought during grain filling on PS II activity in rice. J Plant Physiol. 2005;162(8):903-11. https://doi.org/10.1016/j.jplph.2 004.11.001.

Ramakrishna A, Tam HM, Wani SP, Long TD. Effect of mulch on soil temperature, moisture, weed infestation and yield of groundnut in northern Vietnam[J]. Field Crops Res. 2006;95(2-3):115-25. https://doi.org/10.1016/j.fcr.2005.01.030.

Rao SS, Tanwar SPS, Regar PL. Effect of deficit irrigation, phosphorous inoculation and cycocel spray on root growth, seed cotton yield and water productivity of drip irrigated cotton in arid environment. Agric Water Manag. 2016;169: 14-25. https://doi.org/10.1016/j.agwat.2016.02.008.

Snider JL, Oosterhuis DM, Collins GD, et al. Field-acclimated Gossypium hirsutum cultivars exhibit genotypic and seasonal differences in photosystem II thermostability. J Plant Physiol. 2013;170(5):489-96. https://doi.org/10.1016/j. jplph.2012.11.004.

Stone PJ, Sorensen IB, Jamieson PD. Effect of soil temperature on phenology, canopy development, biomass and yield of maize in a cool-temperate climate. Field Crop Res. 1999;63(2):169-78. https://doi.org/10.1016/S0378-42 90(99)00033-7.

Su J, Ning X, Lin H, et al. Effects of uncovering plastic film on soil temperature of cotton cropland, cotton yield and environment protection. Acta Agri Boreali-Occidentalis Sinica. 2011b;20(3):90-4 (in Chinese with English abstract).

Su JJ, Deng FJ, Lin H, et al. Effects of uncovering plastic film on rhizosphere temperature, dry matter accumulation of organs, yield and fiber quality of upland cotton. Cotton Sci. 2011a;23:172-7 (in Chinese with English abstract).

Sun SJ, Fan YM, Xu ZH, et al. Effects of planting density on soil moisture and corn yield under plastic film mulching in a rain-fed region of Northeast China. Chin J Ecol. 2014;33(10):2650-5. https://doi.org/10.13292/j.1000-4890.2 014.0226.

Tang QY, Zhang CX. Data processing system (DPS) software with experimental design, statistical analysis and data mining developed for use in entomological research. Insect Sci. 2012;20(2):254-60. https://doi.org/10.1111/ j.1744-7917.2012.01519.x.

Tang W, Luo Z, Wen SM, et al. Comparison of inhibitory effects on leaf photosynthesis in cotton seedlings between drought and salinity stress. Cotton Sci. 2007;19(1):28-32. 
Thompson RC, Swan SH, Moore CJ, vom Saal FS. Our plastic age. Philos Trans R Soc B. 2009;364(1526):1973-6. https://doi.org/10.1098/rstb.2009.0054.

Wang FX, Feng SY, Hou XY, et al. Potato growth with and without plastic mulch in two typical regions of northern China. Field Crop Res. 2009;110(2):123-9. https://doi.org/10.1016/j.fcr.2008.07.014.

Wang JX, Pang XA, Wu WM, et al. Analysis on climate productive potential for cotton growth in Aral irrigated area. Arid Zone Res. 2006;23:623-6 (in Chinese with English abstract).

Wang R, Liu GS, Bi QW, et al. Effect of plastic film mulching in whole growth period on the photosynthetic function, yield, and quality of flue-cured tobacco at different elevations in Enshi of Hubei Province. Chin J Ecol. 2010; 29(1):43-9 (in Chinese with English abstract). https://doi.org/10.13292/j.1 000-4890.2010.0061.

Wang YP, Li XG, Zhu J, et al. Multi-site assessment of the effects of plastic-film mulch on dryland maize productivity in semiarid areas in China. Agric For Meteorol. 2016;220:160-9. https://doi.org/10.1016/j.agrformet.2016.01.142.

Wang YZ, Liu RT, Zhang JG. On physiological mechanism of early aging caused by plastic mulching on tomatoes. J Shanxi Agric Univ. 2004;1:60-2. https:// doi.org/10.13842/j.cnki.issn1671-8151.2004.01.017.

Xia ZX, Zhang Y. Comparison test of removal of film before irrigation and irrigation on surface film. Xinjiang Agric Reclam Sci Technol. 1994(2):33.

Xie HX, He S, Zhou JW, et al. Effect of irrigation amount and buried depth of drip irrigation tape on cotton. J Irrig Drain. 2012;31:134-6 (in Chinese with English abstract). https://doi.org/10.13522/j.cnki.ggps.2012.02.033.

Xie WH, Ma SJ, Qi L, et al. The mitigating effects of $\mathrm{Na}^{+}$accumulation on the drought-induced damage to photosynthetic apparatus in cotton seedlings. Acta Ecol Sin. 2015;35(19):6549-56. https://doi.org/10.5846/stxb201403060382.

Xu JW, Zhang XJ, Li ZB, et al. Preliminary study on photosynthetic characteristics of cotton seedlings with different genotypes under drought stress in field experiments. Collection of papers of the 2017 annual meeting and the 9th general meeting of the cotton branch of China Agricultural Society; 2017. p. 103.

Xue HY, Zhang YJ, Liu LT, et al. Responses of spectral reflectance, photosynthesis and chlorophyll fluorescence in cotton during drought stress and rewatering. Sci Agric Sin. 2013;46(11):2386-93. https://doi.org/10.3864/j.issn.0578-1752.2 013.11.024.

Yang X, Zhang Z, Niu Y, et al. Cotton root morphology and dry matter accumulation at different film removal times. Agron J. 2017;109(6):2586-97. https://doi.org/10.2134/agronj2017.06.0310.

Yang ZX, Yang TZ, Zhang XQ, et al. Effects of different mulching patterns on physiological characteristics, yield and quality of flue-cured tobacco. Chin J Soil Sci. 2010;41(2):420-4.

Yu YM, Zhang W, Zhou ZJ. Experimental study on the appropriate film-removal time of mulching between rows of maize. J Maize Sci. 2006(Suppl 1):104-05, 107.

Zhan DX. The spatial distribution of cotton canopy photosynthesis and the physiological characteristics of leaf and non-leaf organs in response to water supply. Ph. D. Thesis. Shihezi: Shihezi Univ; 2014 (in Chinese with English abstract).

Zhang JG, Du SH, Wang YZ, et al. Preliminary study on the physiological mechanism of premature senescence of early cabbage caused by mulch film. China Vegetables. 1995(5):1-3.

Zhang JJ, Fan TL, Dang Y, et al. Effects of uncovering plastic film period and nitrogen amount on the growth indexes and yield of spring maize in loess plateau of East Gansu. Soil Fertilizer Sci China. 2016a(4):90-6. https://doi.org/1 $0.11838 /$ sfsc.20160415.

Zhang WF, Gou L, Wang ZL, et al. Effect of nitrogen on chlorophyll fluorescence of leaves of high-yielding cotton in Xinjiang. Sci Agric Sin. 2003;36(8):893-8.

Zhang ZQ, Wei JJ, Yang XK, et al. Effects of plastic film uncover on soil temperature, moisture level and cotton root growth. Agric Res Arid Areas. 2016b;34:55-61 (in Chinese with English abstract). https://doi.org/10.7606/j. issn. 1000-7601.2016.02.09

Zhao LY, Deng XP, Shan L. Effects of altered water condition on some chlorophyll fluorescence parameters of flag leaves of winter wheat. Chin J Eco-Agric. 2007;15(1): 63-6. (in Chinese with English abstract)

Ready to submit your research? Choose BMC and benefit from:

- fast, convenient online submission

- thorough peer review by experienced researchers in your field

- rapid publication on acceptance

- support for research data, including large and complex data types

- gold Open Access which fosters wider collaboration and increased citations

- maximum visibility for your research: over $100 \mathrm{M}$ website views per year

At BMC, research is always in progress.

Learn more biomedcentral.com/submissions 